\title{
Estudo da microbiota conjuntival de cães portadores de Diabetes mellitus
}

Dissertação apresentada ao

Programa de Pós-Graduação em

Clínica Cirúrgica Veterinária da

Faculdade de Medicina Veterinária e Zootecnia da Universidade de São

Paulo para obtenção do título de Mestre em Medicina Veterinária

Departamento:

Cirurgia

Área de concentração:

Clínica Cirúrgica Veterinária

Orientador:

Prof. Dr. Paulo Sergio de Moraes

Barros

São Paulo 
Autorizo a reprodução parcial ou total desta obra, para fins acadêmicos, desde que citada a fonte.

DADOS INTERNACIONAIS DE CATALOGAÇÃO-NA-PUBLICAÇÃO

(Biblioteca Virginie Buff D’Ápice da Faculdade de Medicina Veterinária e Zootecnia da Universidade de São Paulo)

Shimamura, Graziele Massae

FMVZ

Estudo da microbiota conjuntival de cães portadores de Diabetes mellitus / Graziele Massae Shimamura. - São Paulo : G. M. Shimamura, 2008.

$64 \mathrm{f}$. : il.

Dissertação (mestrado) - Universidade de São Paulo. Faculdade de Medicina Veterinária e Zootecnia. Departamento de Cirurgia, 2008.

Programa de Pós-Graduação: Clínica Cirúrgica Veterinária.

Área de concentração: Clínica Cirúrgica Veterinária.

Orientador: Prof. Dr. Paulo Sergio de Moraes Barros.

1. Cão. 2. Diabetes mellitus. 3. Microbiota. 4. Conjuntiva. I. Título. 


\section{CERTIFICADO}

Certificamos que o Projeto intitulado "Estudo da microbiota conjuntival de cães portadores de diabetes mellitus", protocolado sob o n ${ }^{\circ} 1067 / 2008$, utilizando 60 (sessenta) cães, sob a responsabilidade do Prof. Dr. Paulo Sergio de Moraes Barros, está de acordo com os princípios éticos de experimentação animal da Comissão de Bioética da Faculdade de Medicina Veterinária e Zootecnia da Universidade de São Paulo e foi aprovado "ad referendum".

We certify that the Research "Conjunctival flora of dogs with diabetes mellitus", utilizing 60 (sixty) dogs, protocol number 1067/2008, under the responsibility Prof. Dr. Paulo Sergio de Moraes Barros, agree with Ethical Principles in Animal Research adopted by Bioethic Commission of the School of Veterinary Medicine and Animal Science of University of São Paulo and was approved "ad referendum" of the meeting.

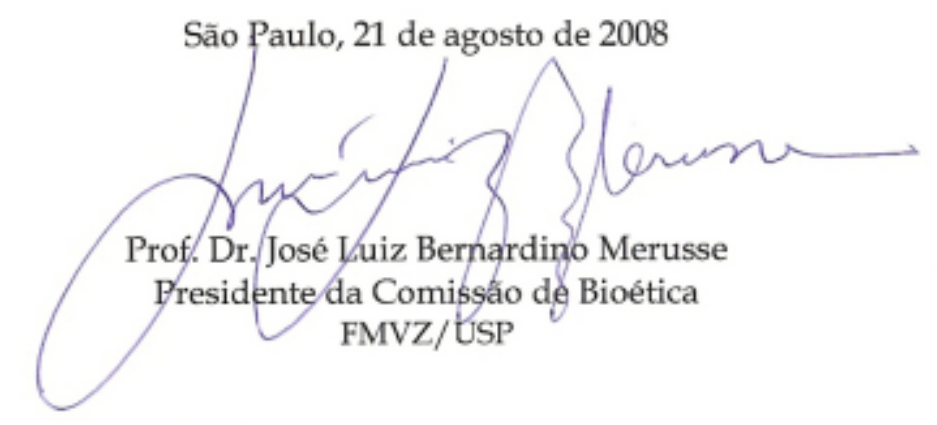




\section{FOLHA DE AVALIAÇÃO}

Nome: Shimamura, Graziele Massae

Título: Estudo da microbiota conjuntival de cães portadores de Diabetes mellitus

Dissertação apresentada ao Programa de PósGraduação em Clínica Cirúrgica Veterinária da Faculdade de Medicina Veterinária e Zootecnia da Universidade de São Paulo para obtenção do título de Mestre em Medicina Veterinária

Data:

Banca Examinadora

Prof. Dr. Instituição:

Assinatura: Julgamento:

Prof. Dr. Instituição:

Assinatura: Julgamento:

Prof. Dr. Instituição:

Assinatura: Julgamento: 
Senhor: Fazei de mim um instrumento de vossa Paz!

Onde houver Ódio, que eu leve o Amor,

Onde houver Ofensa, que eu leve o Perdão.

Onde houver Discórdia, que eu leve a União.

Onde houver Dúvida, que eu leve a Fé.

Onde houver Erro, que eu leve a Verdade.

Onde houver Desespero, que eu leve a Esperança.

Onde houver Tristeza, que eu leve a Alegria.

Onde houver Trevas, que eu leve a Luz!

Ó Mestre,

fazei que eu procure mais:

consolar, que ser consolado;

compreender, que ser compreendido;

amar, que ser amado.

Pois é dando, que se recebe.

Perdoando, que se é perdoado e

é morrendo, que se vive para a vida eterna!

Oração de São Francisco de Assis

"Nós não somos o que gostaríamos de ser Nós não somos o que ainda iremos ser Mas, graças a Deus,

Não somos mais quem nós éramos"

Martin Luther King 
À minha querida mãe, Rosemari, que sempre me apoiou e incentivou a buscar meus objetivos com muito amor, carinho!

Ao meu querido pai, Masanobu, pelo apoio, amor e ao incentivo aos estudos; profissional que sempre admirei.

Aos meus queridos irmãos, Cibele, Gisele e Massaharu; cunhados, Masashi e Nobu; sobrinhos, Yohan, Yago, Vítor e Vinícius, que sempre me apoiaram! Sem eles seria muito difícil prosseguir! 
Aos meus queridos avós maternos Antonio e Ludovina, exemplos de vida, com os quais aprendi que existe amor incondicional! Amo muito vocês! À minha batian Haruko, pelos ótimos momentos e ensinamentos e, ao meu ditian Eijiro, mesmo um pouco distante, com certeza, está me orientando. 
Ao meu noivo, Fábio Nishimura, que me acompanha desde o início da graduação, obrigada pela paciência, atenção, amor e carinho que foram fundamentais na realização deste trabalho. 
Ao Prof. Dr. Paulo Sergio de Moraes Barros, que me acolheu na Oftalmologia Veterinária, pela oportunidade de realizar este trabalho; pela orientação e aprendizado. 
À querida Angélica de Mendonça Vaz Safatle pelos ensinamentos e grande amizade que se firmou durante esses anos, acolhendo-me como parte de sua família e por sempre me incentivar! 


\section{AGRADECIMENTOS}

Ao Prof. Nilson Roberti Benites pela utilização do Laboratório de Doenças Infecciosas para realizar a parte experimental.

À Priscila Anne Melville, muito sensata e serena, pelo grande auxílio no experimento, se tornou uma amiga.

Às grandes amigas e companheiras Adriana Cabral Lustosa, Márcia Pancera Galego e Milena Sefrin Helzel pelos bons momentos, solidariedade e união! Sempre preocupadas comigo, estavam ao meu lado quando mais precisei!

Ao Prof. Dr. Alexandre Lima Andrade pelos primeiros ensinamentos na Oftalmologia Veterinária durante a graduação.

Às amigas, desde minha graduação, Daniela Cagnoto Nogueira e Andréa Rossi Rodrigues, "conselheiras", que sempre me apoiaram!

À amiga Ana Paula Hvenegaard, com seu jeitinho especial conquistou a amizade de todos, inclusive a minha! Obrigada por me ajudar!

Aos queridos amigos da pós-graduação, Daniela Castro, Eduardo Perlmann, Luiz Felipe Barros, Renata Squarzoni, médicos veterinários oftalmologistas que conviveram comigo no serviço de Oftalmologia, pela companhia, amizade e grande auxílio.

Às amigas Fernanda Maria Lopes e Fernanda Hofmann Appollo, que compartilharam momentos difíceis e muito estressantes durante a pós-graduação.

À querida amiga Angélica Maria Brasil Vita, pela amizade, auxílio e pelo estágio concedido na Oftalmolab, laboratório de Microbiologia Ocular.

Aos amigos da Oftalmolab, Raul Ragazzi, Celina Teixeira, Ligia Marques, Simone Marcelino, Carlos Eduardo da Silva Saito e José Antonio Batistuzzo pelo aprendizado na microbiologia ocular e ótimos momentos.

À amiga Ana Carolina Yashima que sempre me apoiou nessa minha jornada, aconselhando e dando forças pra sempre continuar buscando os meus objetivos.

A todos os médicos veterinários do HOVET pela amizade, colaboração e convívio. 
Às secretárias do HOVET, Janilda Sudária Costa e Regiane Guimarães, pelo apoio e colaboração.

Aos secretários do Departamento de Cirurgia, Alessandra Sousa e Belarmino Ney Pereira, pelo auxílio.

Aos amigos da residência, Ana Luiza Mazorra, Melissa Cunha, Fabio Bloch, Luciana Moreno, Leda Barros, Vanice Allemand, Luciana Camignotto pela amizade e apoio.

Aos amigos Joselma Gomes da Silva, Geraldo Natalino Thezi, que me acompanharam e apoiaram nessa jornada, assim como todos os amigos da Administração do Hospital Veterinário, participantes das "reuniões" do café da manhã!

Às secretárias da pós-graduação Claudia, Dayse e Joana pelo auxilio.

Às funcionárias da Biblioteca Virginie Buff D’Ápice da FMVZ/USP, Elza Faquim e Maria de Fátima dos Santos, pelo auxílio na revisão deste trabalho, competência, simpatia e disposição em ajudar.

Aos meus professores da graduação, da Unesp de Araçatuba, instituição da qual me orgulho muito, por construirem a base do meu aprendizado em medicina veterinária, pela amizade e bons momentos que nunca esquecerei. Saudades!

À Faculdade de Medicina Veterinária e Zootecnia da Universidade de São Paulo que me deu condições para a realização deste trabalho.

Aos cães que contribuíram para que este trabalho fosse realizado, meu carinho e respeito.

À minhas "meninas" Chimbica, Mari, Teca e Susi, que trouxeram muitas alegrias e muito amor à minha vida.

À Pucca e ao Nikki, "recém-chegados" em casa, que me mostram a alegria de viver a cada dia.

A todos os residentes, pós-graduandos, estagiários e funcionários que de alguma forma contribuíram para a realização deste trabalho.

À Coordenação de Aperfeiçoamento de Pessoal de Nível Superior (CAPES) pela bolsa concedida. 


\section{RESUMO}

SHIMAMURA, G. M. Estudo da microbiota conjuntival de cães portadores de Diabetes mellitus. [Conjunctival flora in dogs with Diabetes mellitus]. 2008. $64 \mathrm{f}$. Dissertação (Mestrado em Medicina Veterinária) - Faculdade de Medicina Veterinária e Zootecnia, Universidade de São Paulo, São Paulo, 2008.

A microbiota normal exerce função protetora na superfície ocular, competindo por nutrientes e secretando substâncias com propriedades bactericidas, o que dificulta a invasão de patógenos. Animais diabéticos apresentam diferentes alterações ceratoconjuntivais, tais como maior concentração de glicose no filme lacrimal, menor quantidade e qualidade da lágrima e diminuição da sensibilidade corneal, diferenças clinicamente relevantes que podem alterar essa microbiota. Traumas oculares também podem apresentar tal alteração por promoverem a quebra da barreira de proteção da superfície ocular. A correta identificação do agente etiológico, além de proporcionar um tratamento eficiente em alterações oculares, direciona a antibioticoterapia profilática tópica nos casos cirúrgicos e evita o uso abusivo de antibióticos, o que pode levar a destruição da microbiota normal da superfície ocular, facilitando assim o crescimento de bactérias e fungos patogênicos. Com o intuito de minimizar as complicações pós-operatórias das cirurgias intra-oculares, como as facectomias, freqüentemente realizadas nos cães diabéticos por serem predispostos a apresentarem catarata, este estudo visou avaliar a prevalência dos principais microrganismos da microbiota conjuntival de cães diabéticos. Foram avaliadas as microbiotas conjuntivais de 29 cães diabéticos, atendidos no Hospital Veterinário da Faculdade de Medicina Veterinária e Zootecnia da Universidade de São Paulo, totalizando 58 olhos. Estes, não estavam utilizando qualquer medicação tópica e não apresentavam alterações oculares ou doença sistêmica infecciosa que pudesse interferir nos resultados. As amostras foram colhidas do saco conjuntival com auxilio de zaragatoas, cuidando para que não houvesse contaminação pelo contato com pálpebras e cílios. As amostras foram inoculadas em meio enriquecedor Brain Heart Infusion (BHI) e caldo Sabouraud-dextrose e semeados em ágar sangue, MacConkey e Sabouraud-dextrose com cloranfenicol. Os microrganismos foram identificados por suas características morfológicas na bacterioscopia, pela coloração 
de gram e pelas características macro e microscópicas das colônias, além de testes bioquímicos. Houve maior prevalência de Staphylococcus (32,79\%), principalmente coagulase negativos, que são os mais freqüentemente isolados nas infecções oculares: S. klosii, S. simulans, S. capitis, S. pasteuri, S. saprophyticus, S. haemolyticus. Também foram isolados Bacillus sp. (11,48\%), S. intermedius $(6,56 \%)$, Streptococcus sp $(1,64 \%)$ e alguns fungos, como Cladosporium sp e Candida parapsilosis. Não houve crescimento de microrganismos gram negativos, anaeróbios estritos ou facultativos. Sugere-se que os resultados encontrados se relacionam diretamente às alterações ceratoconjuntivais dos animais analisados, local do exame, clima e diferentes raças. Sabendo-se que cães diabéticos são prováveis candidatos à facectomia, intervenção que promove quebra da barreira de proteção da superfície ocular e que existem microrganismos potencialmente patogênicos na conjuntiva destes animais, sugere-se análise da microbiota ocular antes da intervenção cirúrgica, para uso profilático de agentes antimicrobianos.

Palavras-chaves: Cão. Diabetes mellitus. Microbiota. Conjuntiva 
SHIMAMURA, G. M. Conjunctival flora in dogs with Diabetes mellitus. [Estudo da microbiota conjuntival de cães portadores de Diabetes mellitus]. 2008. 64 f. Tese (Mestrado em Medicina Veterinária) - Faculdade de Medicina Veterinária e Zootecnia, Universidade de São Paulo, São Paulo, 2008.

Normal ocular flora avoids infection depriving investor microorganisms of nutrients and by the secretion of bactericidal substances. Diabetic animals usually develop keratoconjunctival abnormalities, such as the higher concentration of glucose in the tear film; qualitative and quantitative tear deficiency and a decrease of the cornea sensitivity, what probably changes their conjunctival flora either. The same alteration may happen after ocular traumas, when the ocular barrier of protection is discontinued. The identification of agent etiology allows the efficient treatment of ocular infections, the prophylactic prescription of antibiotics before surgery and avoids destruction of normal ocular flora or multiplication of pathogens. Aiming to minimize complications on intraocular surgeries, such as facectomies, frequently realized in DM dogs for its predisposition to develop cataract, this study evaluated the prevalence of microorganisms in their conjunctival flora. The conjunctival flora of 29 diabetic dogs (58 eyes), attended at the Ophthalmology Service, of the Veterinary Hospital of the Veterinary College - University of São Paulo were evaluated. These dogs weren't using any kind of eyedrops, didn't present any ocular or systemic disease other than diabetes mellitus, what could change the results. Samples were taken with sterile swabs from the conjunctival sac and inoculated on Brain Heart Infusion (BHI) and Sabouraud-dextrose broth, then sown in blood agar, MacConkey and Sabouraud-dextrose-cloranfenicol. Contamination was avoided during procedure not touching the swab on eyelid or eyelashes. Microorganisms were identified by their morphological aspects at bacterioscopy, gram staining, macro and microscopy characteristics of the colonies and by biochemical tests. Staphylococcus presented the higher prevalence $(32,79 \%)$, mostly the coagulase negative ones (S. klosii, S. simulans, S. capitis, S. pasteuri, S. saprophyticus, S. haemolyticus), which are frequently isolated from ocular infections. Either isolated, were Bacillus sp. $(11,48 \%)$, S. intermedius $(6,56 \%)$, Streptococcus sp $(1,64 \%)$ and some fungus, such as Cladosporium sp and Candida parapsilosis. Gram negative bacteria, anaerobic stricts or facultative were not identified during the study. We suppose that these results are strictly correlated to keratoconjunctival alterations in DM dogs, procedure, weather 
and breed. We conclude that, as DM dogs presents potential pathogens on its conjunctiva and are probable candidates to cataract surgery, which discontinues the ocular barrier of protection, we suggest the identification of the agent etiology before surgery and the proper use of antibiotic before and after any intraocular intervention.

Key-words: Dogs. Diabetes mellitus. Flora. Conjunctiva. 


\section{LISTA DE GRÁFICOS}

Gráfico 1- Raças dos cães diabéticos dos quais foram colhidos as amostras dos sacos conjuntivais...

Gráfico 2 - Representação gráfica dos Staphylococcus coagulase negativo identificados nos cultivos bacteriológicos dos sacos conjuntivais de cães diabéticos 


\section{LISTA DE FIGURAS}

Figura 1 - Zaragatoa com meio de transporte STUART 39

Figura 2 - Colheita de material do saco conjuntival com o auxílio de uma zaragatoa em cão diabético da raça Cocker 40

Figura 3 - Staphylococcus intermedius semeado em meio de ágar sangue .......44 


\section{LISTA DE TABELAS}

Tabela 1 - Raça, sexo, idade, peso, glicemia e tempo de sintomas de Diabetes mellitus dos cães que foram utilizados no estudo São Paulo -2008

Tabela 2 - Microrganismos isolados nos cultivos de conjuntiva de cães portadores de Diabetes mellitus - São Paulo -2008 .46 


\section{LISTA DE ABREVIATURAS E SIGLAS}

dl

decilitro

DM

diabete melito

ed.

edição

F

fêmea

$\mathrm{Kg}$

quilograma

M

macho

$\mathrm{mg}$

miligrama

SRD

sem raça definida 
SUMÁRIO

1 INTRODUÇÃO

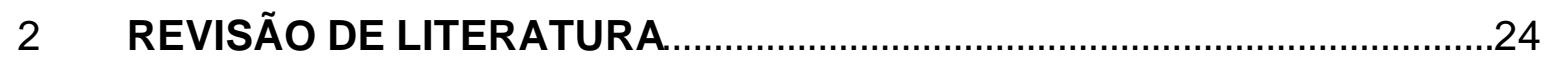

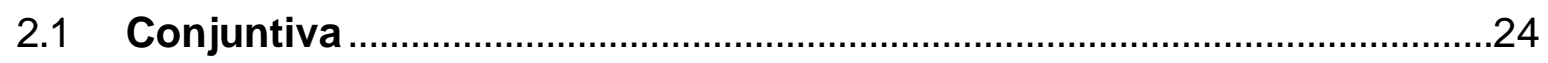

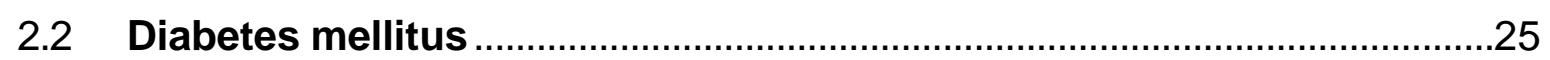

2.2.1 Alterações oculares no paciente diabético .....................................................27

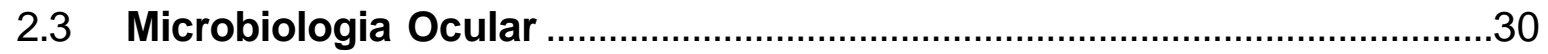

3 OBJETIVO

4 MATERIAL E MÉTODO

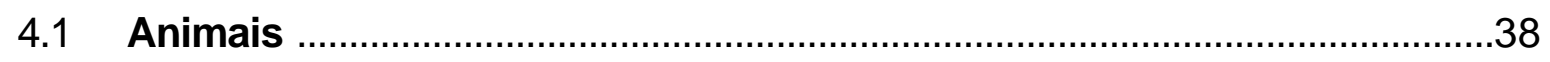

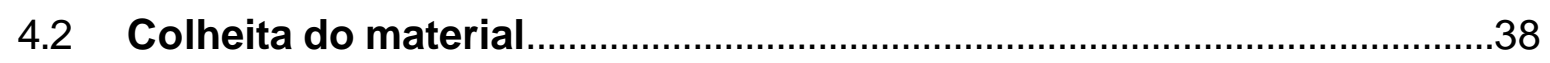

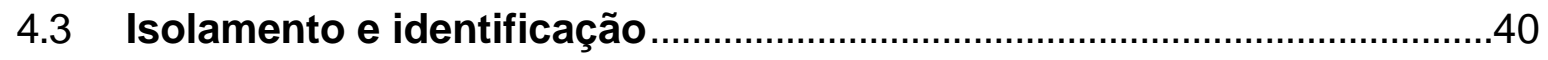

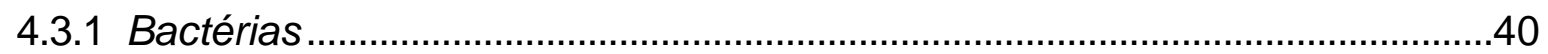

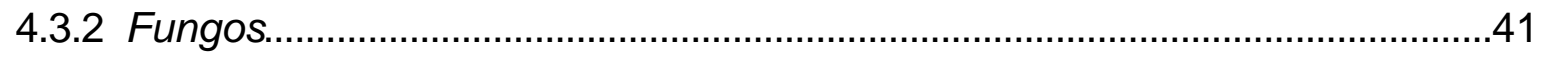

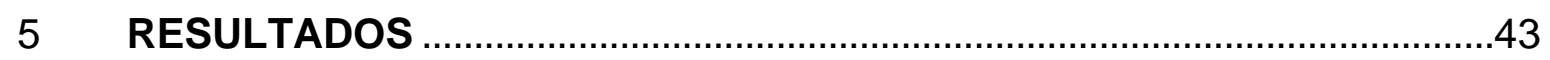

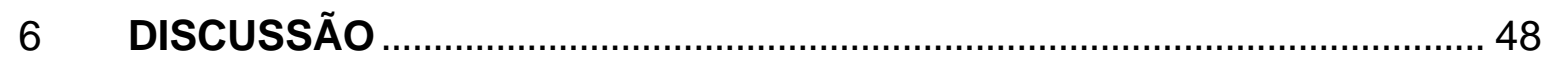

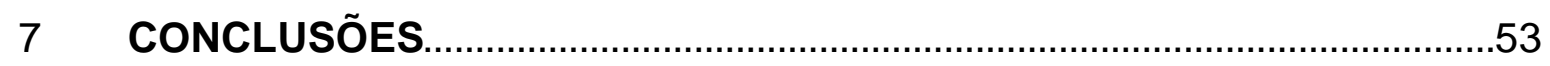

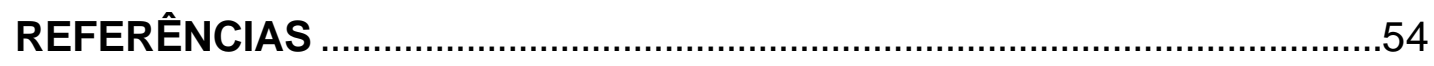




\section{INTRODUÇÃO}

O conhecimento da microbiota ocular é importante fator no diagnóstico da doença ocular externa devido à diversidade de bactérias, fungos, vírus e outros agentes que podem interferir no diagnóstico correto e tratamento efetivo de várias enfermidades oculares.

As infecções têm sua origem aparentemente exógena e podem ocorrer após cirurgias, traumas e terapia com cortisona tópica e, devido a esse motivo, o conhecimento da microbiota, seja bacteriana ou fúngica, é de extrema importância, pois esses microrganismos podem ser os determinantes das infecções intra-oculares (HAMMEKE; ELLIS, 1960).

Existem alterações ceratoconjuntivais nos animais diabéticos na qualidade e quantidade da lágrima e sensibilidade corneal. Devido às diferenças clinicamente relevantes pode-se considerar que pode haver alterações também na microbiota e essa informação pode ajudar a direcionar a antibioticoterapia profilática tópica nos casos cirúrgicos (CULLEN et al., 2005).

As bactérias podem ser isoladas do saco conjuntival de 46 a $90 \%$ dos cães normais. Vários estudos identificaram as bactérias gram positivas como as mais prevalentes enquanto as gram negativas têm sido identificadas em 7 a $8 \%$ do saco conjuntival de cães normais e os fungos são mais raros (HENDRIX, 2007).

A principal manifestação ocular do Diabetes mellitus (DM) nos cães é a formação de catarata. Com os avanços alcançados em Medicina Veterinária, cada vez mais os cães são submetidos aos tratamentos cirúrgicos e, por conseguinte, com o intuito de minimizar as complicações pós-operatórias das cirurgias intraoculares nestes animais, como as facectomias, se faz necessário o estudo da prevalência dos principais microrganismos da microbiota conjuntival. 


\section{REVISÃO DE LITERATURA}

A revisão de literatura foi dividida em alguns tópicos e serão descritos a seguir:

\subsection{Conjuntiva}

A conjuntiva é membrana mucosa translúcida, muito fina, a qual protege o bulbo ocular (OPLUSTIL et al., 2004), recobre a face posterior da pálpebra (conjuntiva palpebral) e superfície anterior do bulbo ocular até o limbo corneal (conjuntiva bulbar), recobre também a face interna e externa da membrana nictitante, sendo denominado de fundo de saco ou fórnice conjuntival, a transição da conjuntiva palpebral para a bulbar (PISANI, 1993; WALDE et al., 1998; HENDRIX, 2008). A conjuntiva desempenha papel na dinâmica da lágrima, proteção imunológica dos olhos, movimentação ocular e cicatrização corneal (HENDRIX, 2008).

É a membrana mucosa mais exposta do organismo, mantendo maior relação com o meio ambiente (MARTIN; ANDERSON, 1981; RISS, 1981; LAVACH, 1990; SLATTER, 1990; PISANI, 1993; ANDRADE, 2002), o que facilita a sua agressão por agentes potencialmente patogênicos (GERDING; KAKOMA, 1990). A conjuntiva pode ser examinada em quase sua totalidade devido a sua anatomia, possibilitando a avaliação de possível necrose, sinais inflamatórios, neoformações ou corpos estranhos (HENDRIX, 1999).

O bulbo ocular possui mecanismos de proteção como o fluxo mecânico da lágrima, ação fagocitária, barreiras mecânicas e ação bacteriostática da lisozima e, qualquer desequilíbrio desses fatores pode predispor a infecções (BISTNER et al., 1969). 


\subsection{Diabetes mellitus}

Diabetes mellitus (DM) é uma endocrinopatia de origem multifatorial, caracterizada por alteração metabólica associada à deficiência absoluta ou relativa de insulina, com hiperglicemia crônica, acima de 250mg/dL (BEAM; CORREA; DAVIDSON, 1999).

Quando o aumento da concentração plasmática de glicose atinge 180 a $220 \mathrm{mg} / \mathrm{dl}$ no cão, excede a capacidade das células tubulares renais em absorver glicose do filtrado glomerular, resultando em glicosúria. Esta, causa diurese osmótica e conseqüente poliúria com polidipsia compensatória. Na ausência relativa ou absoluta de insulina, a glicose não penetra nas células do centro de saciedade, inibindo-o, assim, o indivíduo se torna polifágico devido à hiperglicemia (NGUYEN et al., 1998; FELDMAN; NELSON, 2004). Esses sintomas clínicos associados à hiperglicemia e ou glicosúria resultam no diagnóstico de Diabetes mellitus (NELSON; COUTO, 2001).

Diabetes mellitus espontâneo é relatado na maioria das raças de cães e nos mestiços e é classificado como insulino-dependente, diabetes tipo 1 (DM tipo 1) ou não-insulino dependente, diabetes tipo 2 (DM tipo 2). Nos cães, o mais comum é o DM tipo 1, caracterizado pela deficiência de insulina resultante da destruição ou perda das células $\beta$ das Ilhotas de Langerhans, enquanto que nos gatos, é a DM tipo 2, resultante da resistência associada ou não a produção ou secreção inadequada pelas células $\beta$ das Ilhotas de Langerhans (KANEKO, 1979; GUPTILL et al., 2003; CULLEN; WEBB, 2007b). A característica dos dois tipos é a deficiência da liberação de insulina pelas células $\beta$ pancreáticas e, a maioria dos cães desenvolve o Diabetes mellitus dependente de insulina, ou diabetes tipo 1 (KANEKO, 1979).

Marmor et al. (1982) e Feldman e Nelson (2004) observaram que a incidência do diabete em cães é de 1 para 100 a 1 para 500. Diabete diagnosticada durante o estro ou prenhez pode ser comparada ao diabete gestacional humano. A influência periódica da resistência à insulina associada ao diestro pode contribuir ao risco mais alto enfrentado pelas fêmeas caninas de desenvolver esta doença (RAND et al., 2004). O principal hormônio relacionado com a resistência à insulina durante a gravidez é o hormônio lactogênico placentário, contudo, sabe-se que outros 
hormônios hiperglicemiantes como cortisol, estrógeno, progesterona e prolactina também estão envolvidos (MIRANDA; REIS, 2006).

Também foi proposto que fatores ambientais externos ou internos (químicos, virais, nutricionais) que podem destruir as células $B$, levam à liberação de proteínas dessas células na circulação sanguínea, estimulando a produção de citocinas, porém em cães não foi confirmada esta suspeita, diferentemente do homem (GUPTILL et al., 2003). As citocinas são citotóxicas para as células B, pois induzem a formação de radicais livres. As proteínas dessas células são danificadas pelos radicais livres e apresentadas para o sistema imune numa forma mais antigênica (NERUP, 1994).

Estudos epidemiológicos mostraram que a maioria dos cães diabéticos tinha de 4 a 14 anos de idade e que as fêmeas eram mais suscetíveis que os machos (MARMOR et al., 1982; FELDMAN; NELSON, 2004). Outros estudos mostraram que, no inverno, o diagnóstico do DM tipo 1 nos cães era muito maior, sugerindo que fatores ambientais influenciavam na progressão desta endocrinopatia (RAND et al., 2004; DAVISON; NELMS, 2007).

Estudo realizado por Marmor (1982) demonstrou que os cães da raça Poodle estão em risco crescente de desenvolvimento de DM, enquanto outras raças, como Cocker Spaniel, Pastor Alemão, Collie e Boxer estão em risco decrescente e as fêmeas têm duas vezes mais predisposição para desenvolver diabetes melito do que os machos

A principal lesão encontrada em seres humanos e felinos diabéticos é a amiloidose das ilhotas de Langerhans (O'BRIEN, 1993). A substância amiloide é um polipeptídio secretado juntamente com a insulina. Apesar dos cães produzirem substância amiloide de forma similar aos humanos e felinos, não se identifica freqüência de amiloidose das ilhotas, pois, na maioria dos cães diabéticos, já há destruição dessas ilhotas no momento do diagnóstico. A hiperglicemia aparece quando aproximadamente 75\% das células ß são destruídas (PORTE JR., 1991).

O DM no cão pode levar ao aparecimento de alterações oculares concomitantes, como retinopatia diabética (LANDRY; HERRING; PANCIERA, 2004; SAFATLE, 2008), alterações ceratoconjuntivais (CULLEN et al., 2005) e endoteliais (YEE et al., 1985). 
Catarata secundária é muito freqüente no cão diabético, resultando em cegueira, diferentemente do homem, onde a principal causa de cegueira é a retinopatia diabética (LANDRY; HERRING; PANCIERA, 2004).

Pacientes humanos diabéticos submetidos à cirurgia de catarata apresentam maior ocorrência de complicações relacionadas à inflamação e sangramento. As complicações pós-operatórias mais comuns são a ceratopatia, uveíte anterior serosa e uveíte anterior fibrinosa com formação de sinéquias posteriores e opacificação da cápsula posterior (IVANIC et al., 2005). O DM também é considerado fator de risco para contração da abertura capsular anterior, após capsulorrexis circular contínua empregada na facectomia por facoemulsificação (KATO et al., 2001).

\subsubsection{Alterações oculares no paciente diabético}

Alterações oculares da DM em cães podem ser manifestadas principalmente pela perda de células endoteliais, pleomorfismo e polimegatismo corneais, diminuição da sensibilidade corneal, alteração da vasculatura retiniana tais como a formação de microaneurismas e principalmente pela formação de catarata (CULLEN et al., 2005).

O cristalino é dependente do humor aquoso para sua nutrição e excreção. As fibras e células epiteliais do cristalino dependem quase exclusivamente do metabolismo de glicose para a produção de energia.

A principal via energética da lente é a glicólise anaeróbica e a primeira enzima da via glicolítica é a hexoquinase. A hiperglicemia característica do DM resulta em aumento de açúcar dentro da lente. A ruptura do movimento normal de entrada e saída de água da lente leva a sua formação aguda. A glicose contida no humor aquoso penetra no cristalino por difusão. Em condições normais, esta é convertida em ácido lático pela via anaeróbia (hexoquinase), entretanto, a elevação de sua concentração causa saturação enzimática e ativação da via alternativa (aldose redutase). Esta enzima converte aldeído em sorbitol, que por sua vez se converte em frutose. Sorbitol e frutose não permeiam a membrana celular e são potentes hidrofílicos. 
A aldose-redutase é a primeira enzima desta via, que origina os póliois (sorbitol e dulcinol), os quais não atravessam a membrana celular, permanecendo no interior da lente, resultando em gradiente osmótico, com hidratação das fibras lenticulares e opacificação da lente, que geralmente, é bilateral e inicia-se nas cápsulas anterior e posterior. Por osmose, a água do humor aquoso é absorvida, levando aumento de volume, ruptura e desorganização das fibras lenticulares, com formação de vacúolos e catarata (GLOVER; CONSTANTINESCU, 1997; DAVIDSON; NELMS, 2007; LAUS et al., 2008). O sorbitol é lentamente metabolizado em frutose, e que também, de maneira lenta, atravessa a membrana celular, enquanto o dulcinol não, resultando em alterações lenticulares rápidas (CULLEN; WEBB, 2007a).

As complicações oculares nos pacientes diabéticos humanos são divididas em imediatas e tardias, sendo as tardias muito mais graves e importantes (EHLERS, 1980). Como complicações imediatas, surgem alterações corneais, alterações transitórias na refração, e, mais sérias, porém raras em humanos, as cataratas diabéticas. Neuropatias ópticas e alterações no nervo oculomotor também podem ocorrer. A catarata diabética é rara em seres humanos e ocorre apenas quando o diabetes acomete indivíduos ainda jovens (EPSTEIN, 1976; GELVIN, 1993).

Catarata é a causa mais comum de cegueira tratável e anormalidade genética e o Diabetes mellitus são as causas mais comuns de catarata em cães (ADKINS; HENDRIX, 2005). O Diabetes mellitus induz catarata que geralmente é aguda, progressiva e bilateralmente simétrica (WILKIE et al., 2006).

A formação da catarata diabética depende da espécie acometida, característica individual, idade do paciente quando desenvolveu DM, duração do DM e gravidade da hiperglicemia (quando o diabete não é tratado). Beam, Correa e Davidson (1999) observaram que 50\% dos cães portadores de diabete desenvolvem catarata em aproximadamente 6 meses após o diagnóstico, $75 \%$ em aproximadamente 12 meses e $80 \%$ após 16 meses do diagnóstico, resultando, na maioria dos casos em cegueira.

O tratamento para catarata é cirúrgico (facectomias), sendo o animal diabético ou não, apresenta a mesma taxa de sucesso entre esses dois grupos (BAGLEY; LAVACH, 1994). Reabsorção espontânea da catarata diabética é rara e quando acontece, pode resultar em iridociclite severa irresponsiva ao tratamento, evoluindo para glaucoma ou phthisis bulbi. 
A córnea de um indivíduo diabético é mais susceptível a lesões e cicatriza mais lentamente do que a córnea de um não diabético (CAVALLERANO, 1991). Um desafio para a integridade da córnea é a redução da sensibilidade corneal do indivíduo diabético, resultante de polineuropatia difusa, que afeta o nervo trigêmeo e suas ramificações. Osman (1995) encontrou hipoestesia corneal em $45 \%$ dos 130 pacientes diabéticos examinados e edema microcístico em $11 \%$ desses pacientes. Enquanto esta sensibilidade reduzida é de pouca ou nenhuma conseqüência para um olho saudável, ela pode resultar em ulceração ou abrasão em pacientes com ceratoconjunti vite seca, história prévia de úlceras ou outras alterações de córnea.

O cão diabético apresenta diminuição na quantidade e na qualidade do filme pré-corneal se comparada aos não diabéticos, certificada quantitativamente pelo do teste de lágrima de Schirmer. Esta é uma alteração importante, pois se o animal for submetido ao tratamento cirúrgico para a remoção da catarata, será medicado com atropina que contribui para baixar ainda mais a quantidade de lágrima, potencializando o risco do paciente em desenvolver ceratite ulcerativa pós-cirúrgica (CULLEN et al., 2005).

A qualidade da lágrima pode ser avaliada mensurando-se a estabilidade do filme pré-corneal. Para isso, usa-se o teste denominado de tempo de quebra da lágrima. No paciente diabético este tempo é diminuído, sugerindo deficiência na camada de mucina que pode resultar em ceratoconjuntivite ulcerativa ou não ulcerativa. Há diminuição da sensibilidade corneal que é outro sinal importante no paciente diabético, podendo ser agravado pelo uso tópico contínuo de antiinflamatório não-esteroidal (CULLEN et al., 2005).

Galego et al. (2006) compararam a quantidade, pelo do teste lacrimal de Schirmer, e pH lacrimal em 60 cães, $30 \mathrm{com}$ DM e 30 normais provenientes do Hospital Veterinário da Universidade de São Paulo, observaram que a média dos valores encontrados nos diabético em ambos os testes é discretamente inferior àquela encontrada em cães normais, não havendo diferença estatisticamente significante. 


\subsection{Microbiologia Ocular}

A microbiologia é o ramo da biologia que estuda os seres vivos microscópicos nos seus mais variados aspectos como morfologia, fisiologia, reprodução, genética, taxonomia e também a interação com outros seres e o meio ambiente. É freqüente o uso de corantes para melhor visualização da forma e do tipo de arranjo desses microrganismos.

Um dos exames utilizados na identificação dos microrganismos é a bacterioscopia, utilizando a coloração pelo método de Gram. O termo Gram, vem do nome de Christian Gram, pesquisador dinamarquês que, em 1884, desenvolveu esse método de coloração e que dividiu as bactérias em dois grandes grupos: Grampositivos e Gram-negativos.

A microbiota normal da superfície ocular interfere na invasão de microrganismos privando-os de nutrientes além de secretar substâncias com propriedades bactericidas (FREDRICKSON, 1977; HSU; WISEMAN, 1967).

Em diversos estudos, a microbiota de cães clinicamente sadios apresenta resultados semelhantes, sendo as bactérias gram positivas as mais freqüentes identificadas (MCDONALD; WATSON, 1976; GASKEN, 1980; ANDRADE et al., 2002; TEIXEIRA et al., 2002; PRADO et al., 2005; WANG et al., 2008).

A correta identificação do agente etiológico, além de proporcionar um tratamento eficiente, evita uso abusivo de antibióticos que, segundo Gerding e Kakoma (1990), poderia levar à destruição da microbiota ocular, facilitando o crescimento de bactérias e fungos patogênicos, geralmente após traumatismo com quebra da barreira de proteção da superfície ocular.

Como mencionado anteriormente, as bactérias podem ser colhidas do saco conjuntival em 46 a 90\% dos cães sadios (MCDONALD; WATSON, 1976). As bactérias mais predominantes foram: Staphylococcus sp., Bacillus sp., Corynebacterium sp. e Streptococcus sp. Bactérias anaeróbicas raramente são isoladas e as gram negativas tem sido isoladas em 7 a $8 \%$. Presença de fungos na conjuntiva são raras porém o Cladosporium oxysporum e a Curvularia lunata foram identificados (HENDRIX, 2007). 
Variações no tipo e freqüência dos microrganismos isolados podem ocorrer devido à localização geográfica, técnica de cultivo, raça do animal e estação climática (MARTIN, 1984).

Bistner (1969) isolou bactérias em 76\% das conjuntivas de cães clinicamente sadios, sendo que $70 \%$ dos microrganismos eram Staphylococcus sp. (semelhante ao encontrado por Urban, 1972 - 70,7\%), 12\% Bacillus sp, 7\% gram negativo não especificado e 6\% Streptococcus sp.

McDonald e Watson, no estudo realizado em 1976, obtiveram $22 \%$ dos cultivos negativos, $46 \%$ com um único microrganismo e $32 \%$ com duas ou mais espécies identificadas, sendo as bactérias gram positivas as mais isoladas com Staphylococcus sp., Bacillus sp. e Corynebacterium sp. isolados em mais de $75 \%$ dos cultivos. As bactérias gram negativas correspondiam $8,4 \%$ do total enquanto somente uma bactéria anaeróbia obrigatória foi isolada.

Em 1978, Murphy et al., isolaram bactérias na maioria das amostras de cultivos de conjuntiva de 120 cães com doença ocular (conjuntivite aguda ou crônica, blefarite, dacriocistite crônica ou úlceras de córnea), com a prevalência de Staphylococcus aureus em 68\%, Staphylococcus epidermidis em 27\%, Streptococcus beta-hemolitico em 17\%, Proteus mirabilis 11\%, Escherichia coli 10\% e Bacillus sp. $5 \%$

Speaker et al. (1991), em estudo retrospectivo, usando análise genotípica na identificação do agente etiológico das endoftalmites em humanos, relataram que $82 \%$ dos casos os microrganismos identificados no vítreo eram geneticamente idênticos aos constituintes da microbiota conjuntival, palpebral ou nasal dos pacientes, demonstrando a correlação entre a microbiota externa e a infecção intraocular.

Pisani (1993) observou que a microbiota normal de eqüinos aparenta ter variação de acordo com estação climática, sendo o Staphylococcus epidermidis, Bacillus subtillis e Cândida sp., mais prevalentes no verão e Clostridium sp., Corynebacterium sp., E. coli e Streptococcus sp., no inverno. Porém, Andrew et al. (2003) avaliou a microbiota conjuntival em cem de éguas prenhes na Flórida e observou que não houve diferença significante entre o número ou tipo de microrganismo em relação à sazonalidade.

Bactérias gram positivas predominaram no estudo de Prado et al. (2005) que avaliaram a microbiota de cães saudáveis e cães com ceratite ulcerativa em 
Fortaleza - Ceará, sendo o Staphylococcus o gênero mais isolado e o Staphylococcus intermedius, o mais prevalente em ambos os grupos.

Andrade et al. (2002) e Teixeira et al. (2002), identificaram a microbiota conjuntival de cães sadios na cidade de Araçatuba - SP e São Paulo, respectivamente, e obtiveram predominância de Staphylococcus aureus; além de nos cultivos bacteriológicos em enquanto os cultivos fúngicos mais freqüentes foram Penicilium sp., Dermatium sp., Fusarium sp., Aspergillus sp., Cladosporium sp. em Araçatuba, enquanto em São Paulo nenhum fungo foi isolado.

Martins et al. (2004) estudaram a microbiota conjuntival bacteriana aeróbica de pacientes humanos diabéticos e relataram que o Staphylococcus coagulase negativa foi a bactéria mais isolada neste grupo e no grupo controle (não diabéticos), sendo o Staphylococcus epidermidis o mais prevalente.

Estudo em pacientes humanos diabéticos tipo 1 e 2 que foram submetidos à facectomia, avaliou a microbiota conjuntival pré-operatória dividindo-os em três grupos: 17 pacientes DM tipo 1 (34 olhos), 66 pacientes DM tipo 2 (132 olhos), 50 pacientes normais (100 olhos). Staphylococcus aureus e Staphylococcus epidermidis foram os microrganismos mais frequentemente isolados nos pacientes com Diabetes mellitus e concluiu-se que a microbiota conjuntival dos pacientes diabéticos é diferente dos pacientes não diabéticos. Demonstraram que um tratamento profilático e pós-operatório deve ser considerado, pois pacientes diabéticos são mais predispostos à endoftalmite pós-operatória (geralmente associados microrganismos gram positivos - 75 a 80\%) se comparados ao não diabéticos (BILEN et al., 2007).

Ceratites e conjuntivites bacterianas são síndromes comuns no cão e os agentes isolados são, geralmente, similares àqueles da microbiota conjuntival. $A$ maioria dessas infecções bacterianas não é primária, outras condições debilitantes freqüentemente potencializam a patogenicidade dos organismos da microbiota na superfície ocular (MARTIN, 1984).

Cullen et al. (2005) estudaram os efeitos ceratoconjuntivais nos cães portadores de Diabetes mellitus e observaram que o teor de glicose é maior do que nos cães não diabéticos, os valores dos testes lacrimal de Schirmer e o tempo de quebra da lágrima foram menores nos cães diabéticos e a microbiota ocular identificadas foram bactérias gram positivas (Staphylococcus intermedius, bacilo gram positivo, Staphylococcus coagulase negativo), bactéria gram negativas foram raramente isoladas e não houve crescimento no cultivo para fungos. 
O equilíbrio entre 0 hospedeiro, microbiota normal e microrganismos patogênicos existe devido à defesa inata e adquirida da lágrima e sistema imune. Qualquer destes mecanismos defesa pode ser romper, permitindo que um patógeno se desenvolva (CAVUOTO et al., 2008).

Raramente os fungos são identificados como agente etiológico de doenças oculares externas em cães e gatos, diferentemente do eqüino, que é o agente mais comum. Miller e Albert (1988) relataram ceratite causada por Aspergillus spp e Candida spp em cães e gatos e o isolamento de Candida $s p$, Paelomyces $s p$, Alternatia $s p$ e Geotricum sp na conjuntiva de animais normais.

Outro estudo, Moore et al. (1988) observaram que o Streptomyces natalensis, segunda bactéria mais isolada da conjuntiva normal de eqüino, produz natamicina, uma substância anti-micótica.

Staphylococcus sp. foi o microrganismo mais frequentemente isolado e entre eles, o S. intermedius predominou no saco conjuntival de cães clinicamente normais e nos cães com ceratite ulcerativa em Pequim, China (WANG et al., 2008).

Possíveis fontes de infecção ocular pós-operatória são filme lacrimal, anexos oculares, soluções de irrigação, instrumentais cirúrgicos, microbiota da pele e de sistema respiratório do cirurgião e auxiliar e, ar condicionado. Bactéria é o grupo mais comum dos agentes causadores de endoftalmite e os gram positivos são responsáveis por 60 a $80 \%$ das infecções agudas (CIULLA et al., 2002).

Alguns estudos demonstraram que a maioria das bactérias responsáveis por infecção ocular pós-operatória faziam parte da microbiota conjuntival ou pálpebras dos pacientes humanos (KANELLOPOULOS et al., 1996; SUNARIC-MEGEVAND et al., 1997).

Endoftalmite é uma complicação grave de cirurgia intra-ocular. As pálpebras e conjuntivas têm sido implicadas como sendo a fonte de bactérias mais comum nesses quadros. As culturas nasais de todos os pacientes desse estudo foram positivas para crescimento bacteriano e revelou que $45 \%$ eram Staphylococcus 
coagulase negativo, $17 \%$ Streptococcus viridans, e $8 \% \quad S$. aureus (ALEXANDROU et al., 2006). Este estudo demonstrou uma redução da microbiota bacteriana conjuntival devido à utilização da mupirocina nasal com ou sem o uso de iodopovidona tópica para a realização da cirurgia intra-ocular. (ALEXANDROU et al., 2006).

O fato destas bactérias isoladas de endoftalmites, ceratites e conjuntivites constituírem a microbiota conjuntival de pacientes normais, se faz necessário a escolha profilática pré-operatória eficiente pela possibilidade de resultados pósoperatórios desfavoráveis (GAYOSO et al., 2008)

A cultura de aspirado vítreo é positiva em 50 a $85 \%$ dos casos e 0 Staphylococcus coagulase negativo (Staphylococcus epidermidis) é o patógeno mais freqüentemente isolado, seguido do Staphylococcus aureus e Streptococcus sp., enquanto os gram negativos são responsáveis por $20 \%$ das infecções (SPEAKER et al., 1991). Entre os 50 olhos de pacientes submetidos à facectomia, estudados por Arantes et al. (2005), sete (14,0\%) apresentaram culturas negativas e 43 (86,0\%) culturas positivas e a bactéria mais freqüentemente isolada foi o Staphylococcus coagulase-negativo, encontrada em 27 olhos (54,0\%)

A correta identificação do agente etiológico, além de proporcionar tratamento eficiente, evita uso abusivo de antibióticos que, segundo Gerding e Kakoma (1990), poderia levar a uma destruição da microbiota ocular, facilitando o crescimento de bactérias e fungos patogênicos, geralmente após traumatismo ou cirurgia, quebrando a barreira de proteção da superfície ocular.

Enquanto o uso freqüente e ocasionalmente indiscriminado de antibióticos acarretou o desenvolvimento de resistência bacteriana aos agentes comumente usados (CAVUOTO et al., 2008), os corticosteróides diminuíram a resistência do tecido corneal provavelmente por inibir os mecanismos de defesa celular (FRANCOIS; RIJSSELAERE, 1974; NASISSE; NELMS, 1992) e podem aumentar a virulência de espécies potencialmente patogênicas, permitindo que manifestem sua virulência. 


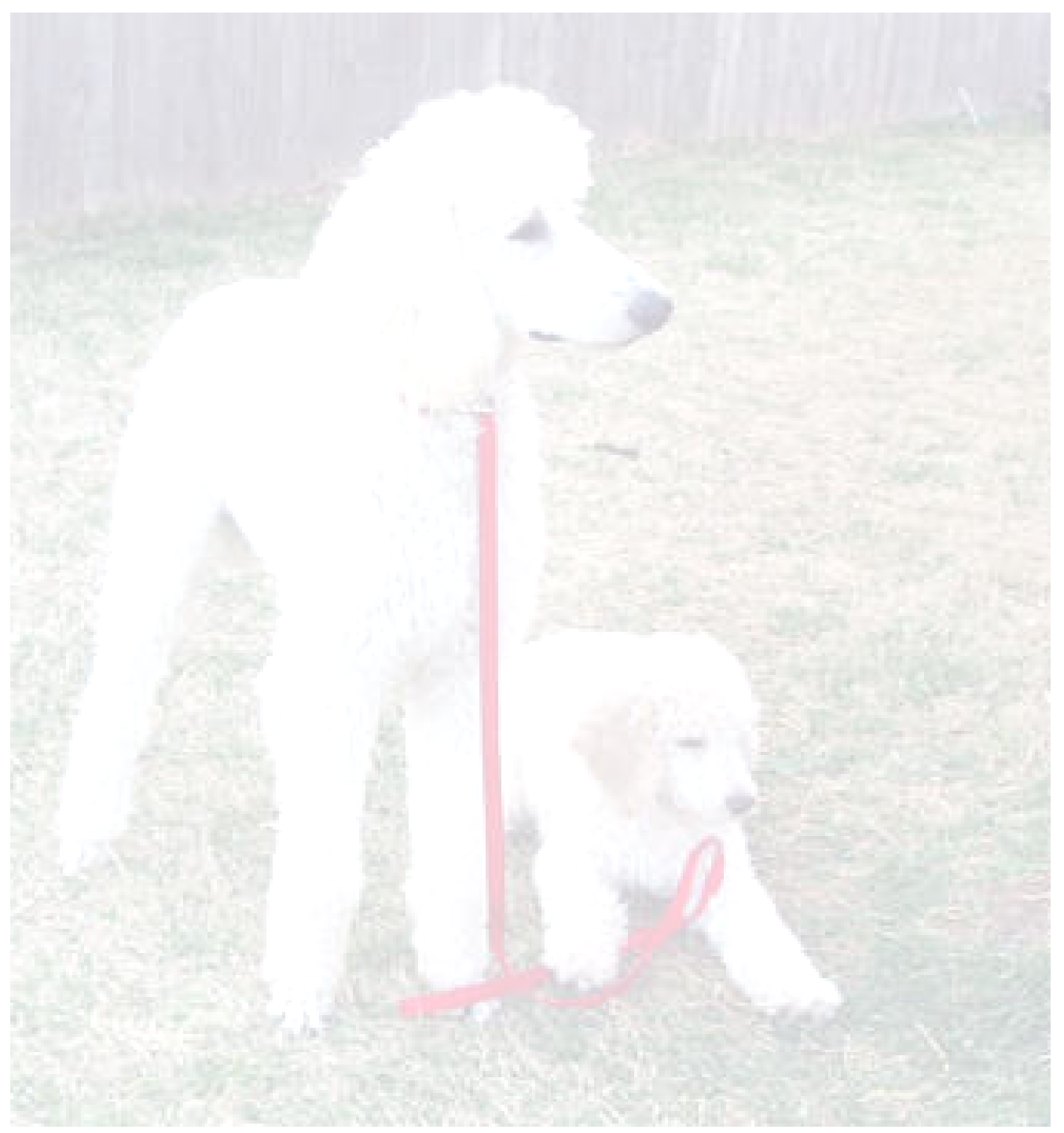

OBJETIVO 


\section{OBJETIVO}

O objetivo deste trabalho foi estudar a microbiota conjuntival de cães portadores de Diabetes mellitus . 
MATERIAL E MÉTODO 


\section{MATERIAL E MÉTODO}

Os animais foram examinados no Laboratório de Investigação em Oftalmologia Comparada do Departamento de Cirurgia da Faculdade de Medicina Veterinária e Zootecnia da Universidade de São Paulo. O protocolo de estudo foi aprovado pela Comissão de Bioética da Faculdade de Medicina Veterinária e Zootecnia da Universidade de São Paulo, sob o nº 1067/2008.

\subsection{Animais}

Foram estudados 58 olhos de 29 animais diabéticos, 25 fêmeas e quatro machos, com idades entre 1 a 14 anos, provenientes do Hospital Veterinário (HOVET) da Faculdade de Medicina Veterinária e Zootecnia da Universidade de São Paulo. O material foi colhido do saco conjuntival de animais diabéticos, com ou sem catarata, independente do sexo e idade que, após avaliação oftalmológica (com o auxilio de lupa de pala ${ }^{1}$ e transiluminador Finoff ${ }^{2}$ ), avaliando conjuntiva, integridade corneal, ausência de secreção, anormalidades ciliares ou palpebrais.

\subsection{Colheita do material}

Foi realizada limpeza das pálpebras com solução fisiológica para eliminação de quaisquer sujidades (PISANI, 1993; CULLEN, 2008), quando necessário, com contenção física, colheu-se o material com de zaragatoas ("swab"), estéreis, com meio de transporte Stuart $^{3}$, umedecido com solução fisiológica rotacionando-as

\footnotetext{
${ }^{1}$ Optivisor ${ }^{\circledR}$

${ }^{2}$ Welsh Allyn ${ }^{\circledR}$

${ }^{3}$ CRAL PLAST ${ }^{\circledR}$
} 
levemente no saco conjuntival da pálpebra inferior, tendo o cuidado de não tocar nos cílios ou rima palpebral para não ocorrer contaminação (Figura 1). Anestésicos tópicos não foram utilizados para a colheita da amostra conjuntival devido ao seu efeito bactericida e bacteriostático, descrito por MULLIN et al. (1997).

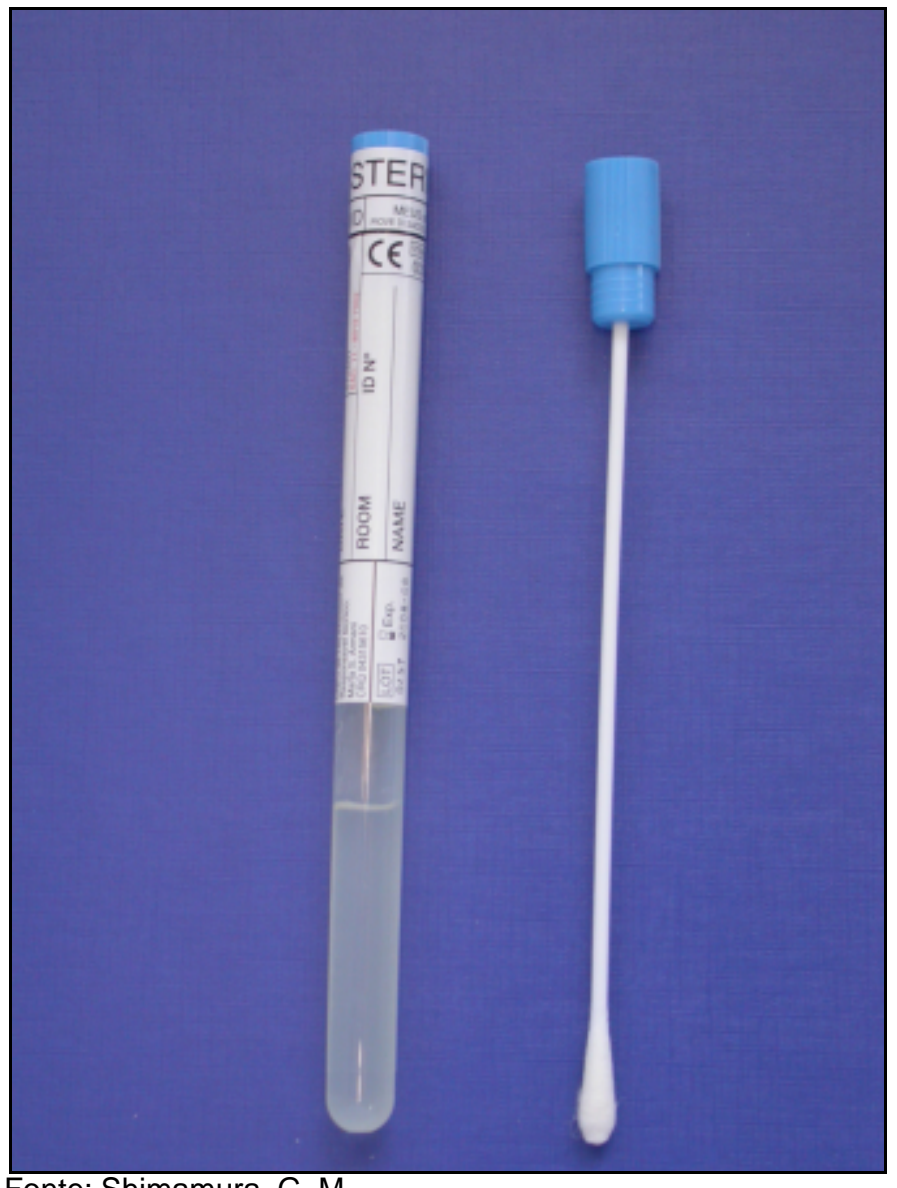

Fonte: Shimamura, G. M.

Figura 1 - Zaragatoa com meio de transporte STUART 


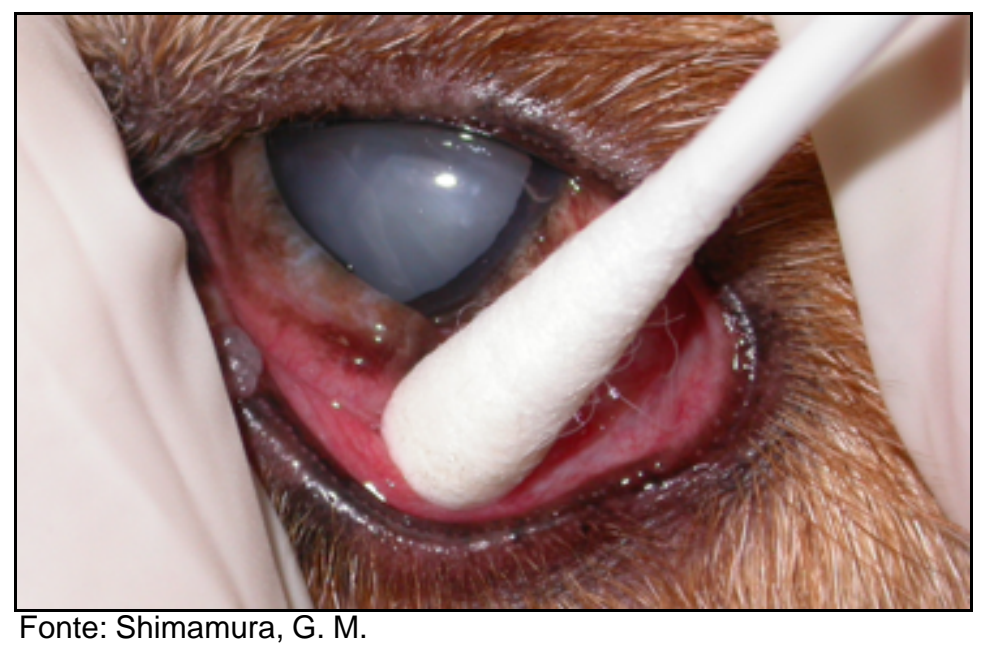

Figura 2 - Colheita de material do saco conjuntival com o auxílio de uma zaragatoa em cão diabético da raça Cocker

\subsection{Isolamento e Identificação}

As amostras foram processadas no Laboratório de Doenças Infecciosas do Departamento Veterinária Preventiva e Saúde da Faculdade de Medicina Veterinária e Zootecnia da Universidade de São Paulo até o prazo de 72 horas, sendo armazenadas de 2 a $8^{\circ} \mathrm{C}$ quando a semeadura não pudesse ser realizada de imediato, com o intuito de retardar o crescimento bacteriano.

\subsubsection{Bactérias}

Para a pesquisa de bactéria aeróbias e anaeróbias facultativas, as zaragatoas foram inicialmente inoculadas em caldo $\mathrm{BHI}$ (Brain and heart infusion) ${ }^{4}$ com incubação a $37^{\circ} \mathrm{C}$ por 24 horas e também semeadas em Ágar sangue de carneiro $(5 \%)^{5}$ e ágar MacConkey ${ }^{6}$, com incubação em aerobiose a $37^{\circ} \mathrm{C}$, com leituras em 24-96 horas. As amostras cultivadas em caldo BHI foram posteriormente semeadas

\footnotetext{
${ }^{4}$ Brain and heart infusion - Oxoid - Hampshire - UK

${ }^{5}$ Blood Agar base - Oxoid - Hampshire - UK

${ }^{6}$ Mac Conkey Agar - Oxoid - Hampshire - UK
} 
em ágar sangue de carneiro (5\%) e ágar MacConkey, com incubação destas realizada de forma similar à descrita anteriormente para o cultivo inicial. Os microrganismos isolados foram identificados de acordo com Lennette (1985) e classificados segundo Krieg e Holt (1994) e Murray et al. (1999).

Foram analisadas as seguintes características para identificação das espécies de Staphylococceus isoladas: pigmento da colônia, crescimento em aerobiose, teste da catalase, coagulase, hemolisina, oxidase, urease, produção de acetoína, redução de nitrato, resistência à novobiocina, resistência à polimixina $B$, beta-galactosidase, produção de ácidos a partir de trealose, manitol, manose, arabinose, maltose, lactose, sacarose, rafinose e xilose.

\subsubsection{Fungos}

Para pesquisa de leveduras e fungos filamentosos, as zaragatoas foram inoculadas em caldo Sabouraud-dextrose e semeados em ágar Sabouraud-dextrose com cloranfenicol, com incubação em aerobiose em temperatura ambiente, com leituras diárias durante 07 dias. Após 03 dias de incubação as amostras cultivadas em caldo foram semeadas em ágar Sabouraud-dextrose com cloranfenicol, com incubação destas realizada de forma similar à descrita anteriormente para o cultivo inicial. A identificação das leveduras foi realizada através de características macro (características das colônias em meio sólido e líquido) e microscópicas: produção de tubo germinativo, produção de pseudomicélio e/ou micélio, bem como provas fisiológicas: fermentação de glicose, maltose, sacarose, galactose, trealose, celobiose e lactose; assimilação de glicose, maltose, sacarose, lactose, rafinose, melibiose, galactose, celobiose, ramnose, eritritol, sorbitol, manitol, arabinose, trealose, inositol, dulcitol, xilose, peptona e nitrato de potássio; produção de urease (LARONE, 1995; LODDER, 1970; KREGER-VAN-RIG, 1984). Os fungos filamentosos foram identificados utilizando-se a descrição das características macroscópicas e microscópicas, de acordo com Barnet \& Hunter (1972); Larone (1995) e Von Arx (1974). 
RESULTADOS 


\section{RESULTADOS}

Os 29 animais (Tabela 1) avaliados neste trabalho, somando 58 olhos, eram de diversas raças: Poodle, sem raça definida - SRD, Dachshund, Rottweiller, Terrier Brasileiro, Labrador, Cocker Spaniel, Dálmata, Pastor Belga, Pinscher (Gráfico 1).

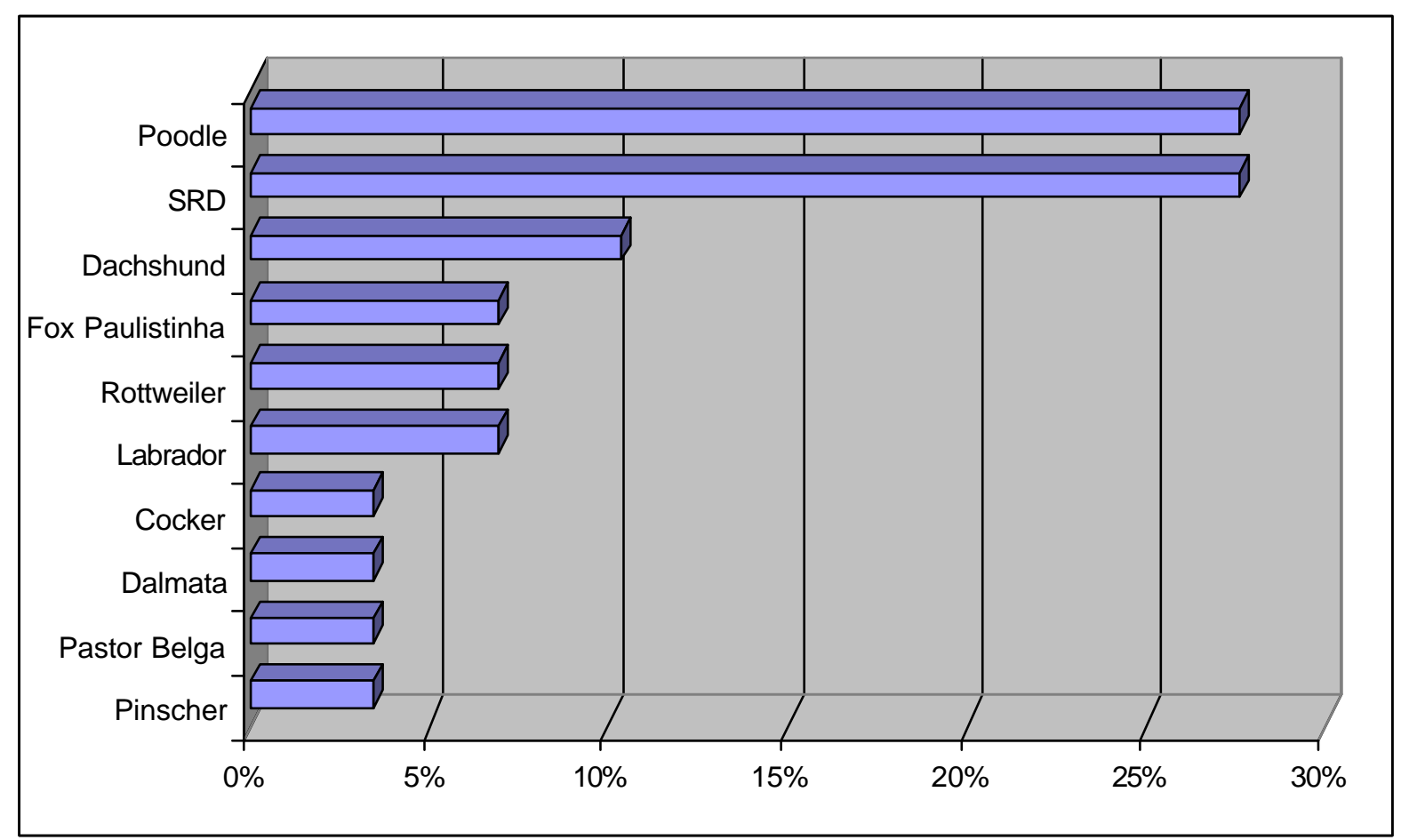

Gráfico 1 - Raças dos cães diabéticos dos quais foram colhidos as amostras dos sacos conjuntivais

Dentre estes animais, 86,20\% eram fêmeas, 64\% castradas, com idade média de 9,3 anos, variando entre 1 e 14 anos. Eram portadores de catarata $69 \%$ dos animais. 
Observou-se que 48,3\% dos animais apresentavam hiperglicemia (acima de $250 \mathrm{mg} / \mathrm{dl}$ ) e que destes, seis animais tiveram o Diabetes mellitus diagnosticado em menos de 30 dias, porém apresentavam sintomas como poliúria, polidipsia, polifagia e perda de peso há, no mínimo, dois meses e, por esse motivo foi considerado o tempo de sintomas do diabetes.

Os cultivos foram positivos (Tabela 2) em $51,67 \%$ dos olhos amostrados, sendo que seis olhos apresentaram mais de um microrganismo isolado. Foram identificados 11 microrganismos do saco conjuntival dos animais diabéticos, sendo $38 \%$ Staphylococcus. Dentre estes, $6,67 \%$ eram estafilococos coagulase positivo e somente $\circ$ S. intermedius (Figura 3 ) foi identificado, enquanto $31,67 \%$ eram de Stafilococos coagulase negativos: S. klosii, S. simulans, S. capitis, S. pasteuri, S. saprophyticus, S. haemolyticus (Gráfico 2).

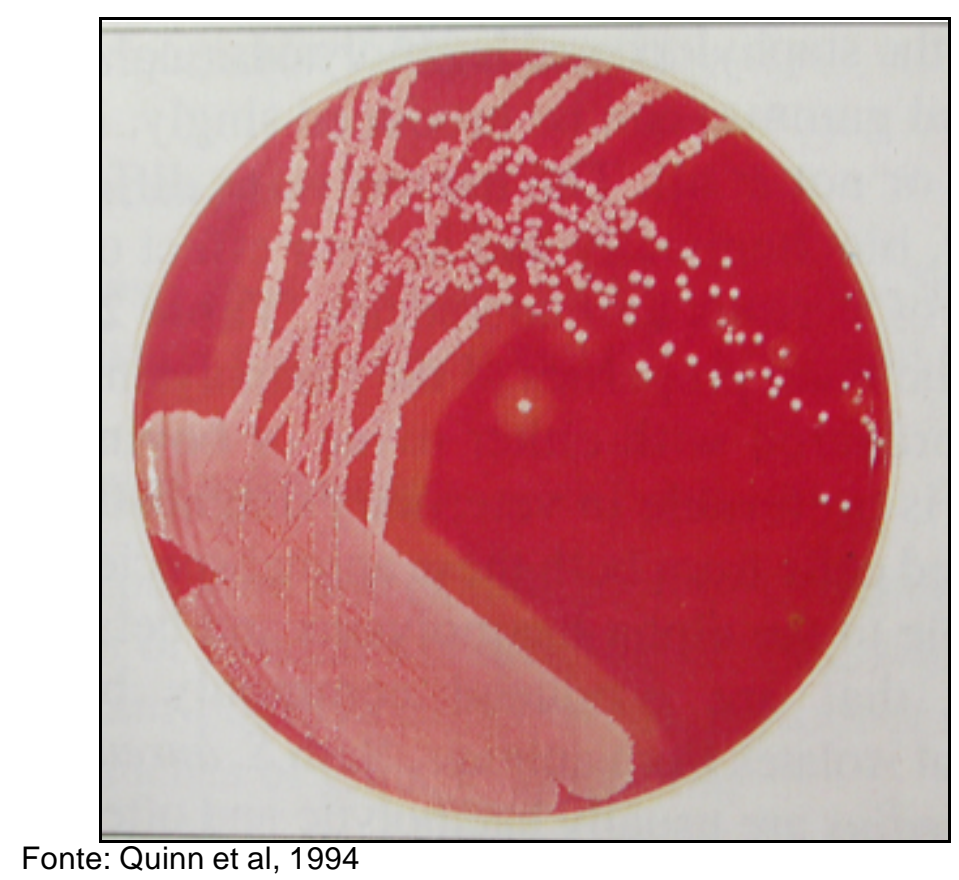

Figura 3 - Staphylococcus intermedius semeado em meio de ágar sangue 
Tabela 1 - Raça, sexo, idade, peso, glicemia e tempo de sintomas de Diabetes mellitus dos cães que foram utilizados no estudo - São Paulo -2008

\begin{tabular}{|c|c|c|c|c|c|}
\hline Raça & Sexo & $\begin{array}{l}\text { Idade } \\
\text { (anos) }\end{array}$ & Peso (kg) & $\begin{array}{l}\text { Glicemia } \\
\text { (mg/dl) }\end{array}$ & $\begin{array}{l}\text { Sintomas de } \\
\text { D. M. (dias) }\end{array}$ \\
\hline Cocker & $M$ & 10 & 15 & 287 & 720 \\
\hline Dachshund & $F$ & 8 & 8,1 & 55 & 90 \\
\hline Dachshund & $\mathrm{F}$ & 9 & 8,6 & 110 & 270 \\
\hline Dachshund & $F$ & 9 & 6 & 209 & 840 \\
\hline Dalmata & $\mathrm{F}$ & 11 & 22,8 & 157 & 360 \\
\hline Fox Paulistinha & M & 10 & 8,5 & 200 & 300 \\
\hline Fox Paulistinha & $\mathrm{F}$ & 13 & 6,2 & 75 & 1080 \\
\hline Labrador & $\mathrm{F}$ & 1 & 29,2 & 102 & 360 \\
\hline Labrador & $F$ & 9 & 30,3 & 303 & 540 \\
\hline Pastor Belga & $F$ & 11 & 32,7 & 408 & 270 \\
\hline Pinscher & $\mathrm{F}$ & 5 & 3,8 & 374 & 60 \\
\hline Poodle & $\mathrm{F}$ & 7 & 7 & 246 & 30 \\
\hline Poodle & $\mathrm{F}$ & 7 & 4,5 & 492 & 60 \\
\hline Poodle & $\mathrm{F}$ & 7 & 4,6 & 307 & 150 \\
\hline Poodle & $F$ & 9 & 9,7 & 360 & 120 \\
\hline Poodle & $F$ & 11 & 15,6 & 266 & 360 \\
\hline Poodle & $F$ & 11 & 10,4 & 600 & 60 \\
\hline Poodle & $F$ & 12 & 7,2 & 232 & 1080 \\
\hline Poodle & $F$ & 12 & 8,9 & 437 & 90 \\
\hline Rottweiler & $\mathrm{F}$ & 3 & 43 & 210 & 360 \\
\hline Rottweiler & $M$ & 8 & 36,5 & 545 & 60 \\
\hline SRD & $F$ & 8 & 6,3 & 187 & 240 \\
\hline SRD & $\mathrm{F}$ & 9 & 12 & 242 & 90 \\
\hline SRD & $M$ & 10 & 22,6 & 382 & 30 \\
\hline SRD & $F$ & 10 & 13,1 & 135 & 150 \\
\hline SRD & $\mathrm{F}$ & 12 & 6,8 & 454 & 90 \\
\hline SRD & $\mathrm{F}$ & 12 & 6,1 & 429 & 120 \\
\hline SRD & $\mathrm{F}$ & 12 & 16,7 & 155 & 1080 \\
\hline SRD & $\mathrm{F}$ & 14 & 24,7 & 106 & 210 \\
\hline
\end{tabular}

F: fêmea; M: macho, SRD: sem raça definida; D.M.: Diabetes mellitus 
Tabela 2 - Resultados dos cultivos de conjuntiva de cães portadores de Diabetes mellitus São Paulo -2008

\begin{tabular}{lcc}
\hline \multicolumn{1}{c}{ RESULTADO } & $\mathrm{n}$ & $\%$ \\
\hline Negativo & 29 & $47,54 \%$ \\
Staphylococcus coagulase negativa & 20 & $32,79 \%$ \\
Bacillus sp. & 7 & $11,48 \%$ \\
Staphylococcus intermedius & 4 & $6,56 \%$ \\
Streptococcus sp. & 1 & $1,64 \%$ \\
\hline Total & $\mathbf{6 1}$ & $\mathbf{1 0 0 , 0 0 \%}$ \\
\hline
\end{tabular}

$\mathrm{n}=$ número de cultivos

Houve a identificação de apenas dois tipos de fungos: Candida parapsilosis e Cladosporium sp. em dois olhos de animais distintos, nos quais também houveram crescimento bacteriano.

Não houve crescimento de microrganismos gram negativos, anaeróbios estritos ou facultativos.

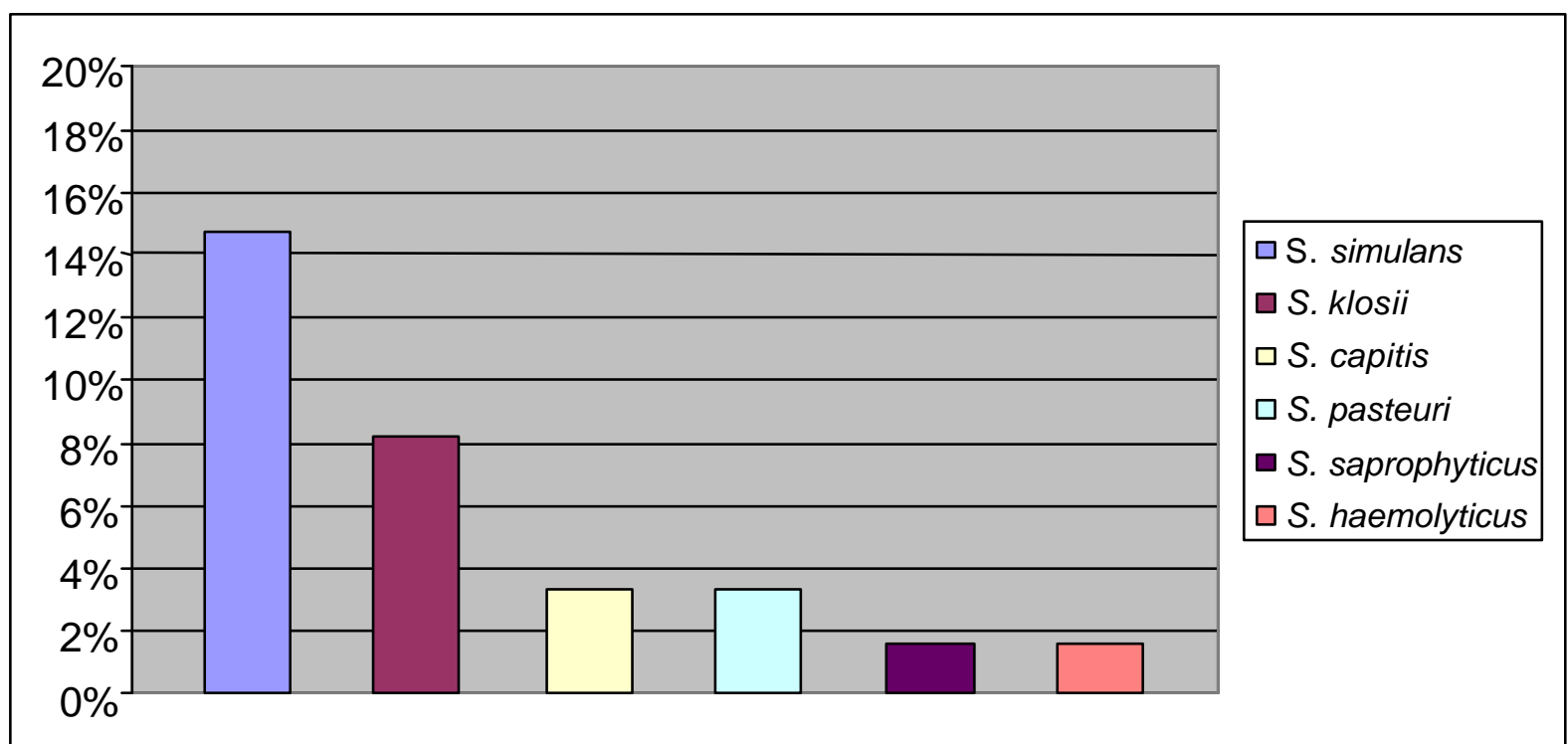

Gráfico 2 - Representação gráfica dos Staphylococcus coagulase negativo identificados nos cultivos bacteriológicos dos sacos conjuntivais de cães diabéticos 


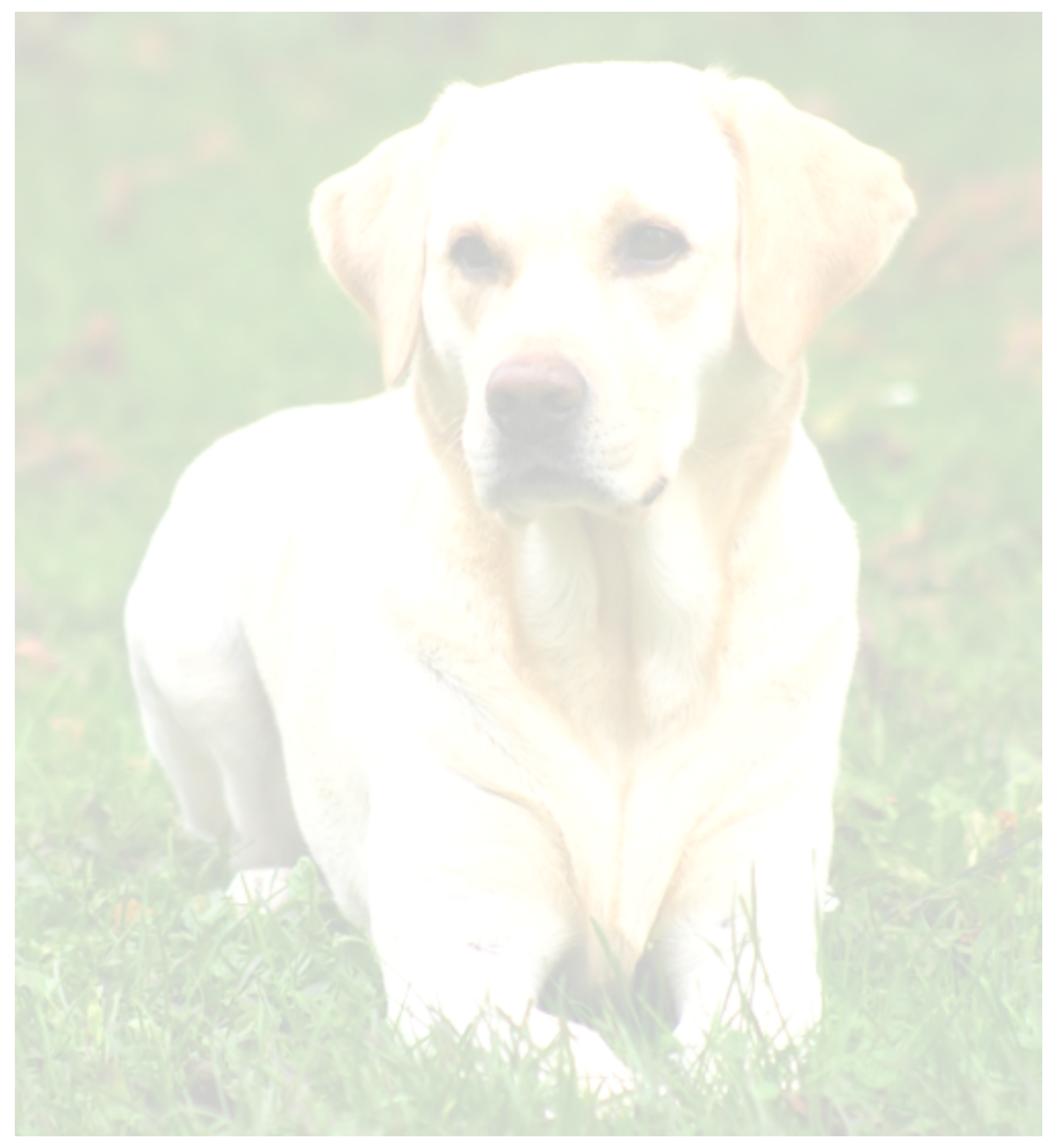

DISCUSSÃO 


\section{DISCUSSÃo}

Com o crescente desenvolvimento das pesquisas na medicina veterinária, diagnósticos são realizados mais rapidamente e tratamento precoce direcionado é aplicado, o que tem aumentado a sobrevida dos animais. Por esse motivo, a oftalmologia veterinária diagnostica várias alterações oculares nos pacientes diabéticos como ceratoconjuntivite, catarata e retinopatia diabética (BEAM; CORREA; DAVIDSON, 1999; CULLEN et al., 2005; CULLEN; WEBB, 2007b).

O filme lacrimal pré-corneal mantém uma superfície ocular opticamente uniforme, removendo corpos estranhos de córnea e conjuntiva, também lubrificandoas; provendo nutrientes para córnea que é avascular e, em algumas espécies, controlando a microbiota local (GUM; GELATT; ESSON, 2007).

Dos 29 animais, 27,59\% eram da raça Poodle. Um estudo avaliou os padrões epizoóticos para o Diabetes melittus em cães e identificou o Poodle como raça de risco significante para o desenvolvimento da doença (MARMOR et al., 1982). Gershwin (1975) suspeitou da herança genética da diabetes melito, no cão, quando identificou a presença da doença numa família da raça Poodle Miniatura.

Neste estudo, as amostras foram colhidas de ambos os olhos devido ao número reduzido de pacientes diabéticos, sem sinais de inflamação ou infecção ocular, sem medicações tópicas ou sistêmicas e sem doenças concomitantes, o que restringiu alguns animais na inclusão neste estudo.

O método de colheita necessita de mínima colaboração do animal para ser executado e foi necessária somente leve contenção física da cabeça para realização da técnica proposta, evitando que a zaragatoa tocasse nas pálpebras ou cílios para não haver contaminação

Os meios de transporte e de cultivos utilizados se mostraram adequados e muito úteis para a realização desses exames $\mathrm{O}$ meio de transporte Stuart por ter carência de fonte de nitrogênio e, também por ser um meio sólido, impede consideravelmente a multiplicação dos microorganismos e a composição nutritiva garante sua sobrevivência. 
A maioria das bactérias encontradas na microbiota conjuntival é considerada não patogênica desde que haja a integridade do epitélio corneal. Nos casos de soluções de continuidade, porém, esses microrganismos podem ser oportunistas infiltrando no estroma corneal, formando uma úlcera infectada (BROOKS et al., 2000; ANDREW et al., 2003)

Alguns autores realizaram o cultivo de apenas um olho de cada animal, como descrito primariamente Urban (1972), que observou uma semelhança no resultado do isolamento entre os olhos do mesmo animal, entretanto obtivemos esta semelhança em 7 casos.

São identificadas microbiotas conjuntivais de animais normais, sendo as bactérias gram positivas as mais comumente isoladas em várias espécies: cães (BISTNER; ROBERTS, 1969; MCDONALD; WATSON, 1976; GASKIN, 1980; GERDING JR.; KAKOMA, 1990; ANDRADE et al.; 2002), eqüinos (LUDVALL, 1967; MOORE et al., 1988; PISANI, 1993; ANDREW et al., 2003), onça pintada e parda (MANCINI, 2005), coelhos (COOPER; MCLELLAN; RYCROFT, 2001), castores canadenses (CULLEN, 2003).

Corroborando com os estudos de McDonald e Watson (1976); Gaskin (1980), Andrade et al. (2002) e Kudirkiene, Zilinskas e Siugzdaite (2006), no qual as bactérias gram positivas correspondiam em mais de $70 \%$ dos cultivos de conjuntiva em cães, o presente estudo obteve bactérias gram positivas em todos os cultivos bacteriológicos.

As principais bactérias foram as gram positivas coagulase negativas, diferentemente dos microrganismos isolados em cães clinicamente normais, não diabéticos, nos quais os Staphylococcus aureus foi o mais prevalente (ANDRADE et al., 2002; TEIXEIRA et al., 2002).

Os estafilococos são cocos Gram-positivos, catalase positivos, que tendem a formar agrupamentos semelhantes a cachos de uva. Os estafilococos são amplamente distribuídos na natureza e fazem parte da microbiota normal da pele e mucosas de mamíferos e aves. Atualmente o gênero Staphylococcus é composto por aproximadamente 27 espécies, sendo que algumas são freqüentemente associadas a uma ampla variedade de infecções de caráter oportunista, em seres humanos e animais. 
Estafilococos coagulase-negativo representam atualmente um dos mais comuns agentes causais de infecções nosocomiais. Destacam-se pela capacidade de aderência à materiais biossintéticos, imprescindíveis e largamente utilizados na prática hospitalar, o que os tornam microrganismos patógenos potenciais em sérias infecções (ALVARENGA et al., 2003)

Os corticosteróides podem diminuir a resistência tecidual, possivelmente por inibição dos mecanismos de defesa celular e aumentar a virulência de espécies sabidamente patogênica, permitindo que espécies comensais manifestem sua virulência. (FRANCOIS; RIJSSELAERE, 1974; RICHTER et al., 2003).

Embora a freqüência de ceratites micóticas seja maior em eqüinos e raro em cães e gatos, espécies de Aspergillus spp, Candida spp, Penicillium spp e Clasdosporium spp têm sido isoladas da conjuntiva de cães e gatos, sendo as duas primeiras as mais freqüentes em ceratites fúngicas (GERDING; KAKOMA, 1990).

Neste presente estudo, somente dois fungos foram isolados e identificados, como a Candida parapsilosis e Cladosporium sp. Ando e Takatori (1982) tiveram resultados semelhantes quando compararam a microbiota fúngica do saco conjuntival de pacientes humanos normais e doentes em Kanagawa, Japão, observando que em ambos os grupos houve o crescimento de Cândida sp. e Cladosporium sp., foram os mais prevalentes.

Samuelson, Andresen e Gwin (1984) que observaram fungos em 22\% dos cães, a maior prevalência dos fungos foi isolada da conjuntiva de eqüinos e bovinos, se comparados aos cães e gatos e que isso pode estar associado ao tamanho do bulbo ocular, e maior superfície exposta ao ambiente.

Vários estudos foram realizados direcionados à microbiota normal de cães (URBAN et al., 1972; MCDONALD; WATSON, 1976; LAVACH et al., 1977). Variações encontradas no estudo podem ser devidas ao local de exame, estação climática, raça dos cães (URBAN et al., 1972), temperatura, idade do paciente, exposição ao ambiente (MOELLER et al., 2005).

Bistner et al. (1969) e Urban et al. (1972) relatam que a presença de potenciais patógenos na conjuntiva dos cães justifica o uso profilático com agentes antimicrobianos nas soluções de continuidade, antes e após serem submetidos a cirurgias.

A anestesia geral e a administração tópica e sistêmica e sulfato de atropina têm sido relatados como causa temporária de redução da parte aquosa da lágrima 
em cães, aumentando o risco de desenvolvimento de ceratites ulcerativas e possibilidade de contaminação secundária causada por microrganismos da microbiota.

A microbiota do animal diabético é diferente daquela do animal não diabético, comparando-se à literatura $e$ isto pode estar relacionado à maior concentração de glicose na lágrima, diminuição da sensibilidade corneal, menor quantidade e qualidade do filme lacrimal (CULLEN; IHLE; WEBB, 2005).

Provavelmente os resultados encontrados se relacionam diretamente às alterações ceratoconjuntivais dos animais analisados, local do exame, clima e diferentes raças. Sabendo-se que cães diabéticos são prováveis candidatos à facectomia, intervenção que promove quebra da barreira de proteção da superfície ocular e que existem microrganismos potencialmente patogênicos na conjuntiva destes animais, indica-se análise da microbiota ocular antes da intervenção cirúrgica, para uso profilático de agentes antimicrobianos. 
CONCLUSÃO 


\section{CONCLUSÃO}

Baseados nos resultados obtidos podemos concluir que:

Houve a prevalência de bactérias, principalmente Staphylococcus coagulase negativo (32,79\%), tais como: S. klosii, S. simulans, S. capitis, S. pasteuri, S. saprophyticus, S. haemolyticus.

Foram identificados dois fungos: Cândida parapsilosis e Cladosporium sp. 


\section{REFERÊNCIAS}

ADKINS, E. A.; HENDRIX, D. V. H. Outcomes of dogs presented for cataract evaluation: a retrospective study. Journal of the American Animal Hospital Association, v. 41, p. 235-240, 2005.

ALEXANDROU, T. J.; HARIPRASAD, S. M.; BENEVENTO, J.; RUBIN, M. P.; SAIDEL, M.; KSIAZEK, S.; THOMPSON, K.; BOONLAYANGOOR, S.; MIELER, W. F. Reduction of preoperative conjunctival bacterial flora with the use of mupirocin nasal ointment. Transactions of the American Ophthalmological Society, v. 104, p. 196-201, 2006.

ALVARENGA, A. C.; MOREIRA, E. S. A.; MATTA MACHADO, G.; RICARDO, S. B. Avaliação in vitro da susceptibilidade antimicrobiana e fatores de risco associados à infecções causadas por Staphylococcus spp. coagulase-negativo resistentes à oxacilina. 2003. 112 f. Dissertação (Mestrado em Ciências Biológicas) - Faculdade de Medicina, Universidade Federal de Minas Gerais, Minas Gerais, 2003.

ANDO, N.; TAKATORI, K. Fungal flora of the conjunctival sac. American Journal of Ophthalmology, v. 94, p. 67-74, 1982.

ANDRADE, A. L.; STRINGHINI, G.; BONELLO, F. L.; MARINHO, M.; PERRI, S. H. V. Microbiota conjuntival de cães sadios da cidade de Araçatuba-SP. Arquivos Brasileiros de Oftalmologia, v. 65, n. 3, p. 323-336, 2002.

ANDREW, S. E.; NGUYEN, A.; JONES, G. L.; BROOKS, D. E. Seasonal effects on the aerobic bacterial and fungal conjunctival flora of normal thoroughbred brood mares in Florida. Veterinary Ophthalmology, v. 6, n. 1, p. 45-50, 2003.

VON ARX, J. A. The genera of fungi sporulating in pure culture. 2. ed. Vanduz: J. Cramer, 1974, p. 351.

BAGLEY, L. H.; LAVACH, J. D. Comparison of postoperative phacoemulsification results in dogs with and without diabetes mellitus. Journal of American Veterinary Medical Association, v. 205, n. 8, p. 1165-1169, 1994.

BARNETT, H. L.; HUNTER, B. B. Illustrated genera of imperfect fungi. 3. ed. Minneapolis: Burgess Publishing Co., 1972. 
BEAM, S.; CORREA, M. T.; DAVIDSON, M. G. A retrospective-cohort study on the development of cataracts in dogs with diabetes melittus: 200 cases. Veterinary Ophthalmology, v. 2, p. 169-172, 1999.

BILEN, H.; ATES, O.; ASTAM, N.; USLU, H.; AKCAY, G.; BATCAL, O. Conjunctival flora in patients with type 1 or type 2 Diabetes Mellitus. Advances in therapy, v. 24, n. 5, p. 1028-1035, 2007.

CAVALLERANO, J. D. A review of non-retinal ocular complications of diabetes mellitus. Journal of American Optometry Association, v. 61, n. 7, p. 533-543, 1991.

CAVUOTO, K.; ZUTSHI, D.; KARP, C. L.; MILLER, D.; FEUER, W. Update on bacterial conjunctivitis in South Florida. Ophthalmology, v. 115, n. 1, p. 51-56, 2008.

CIULLA, T. A.; STARR, M. B.; MASKET, S. Bacterial endophthalmitis prophylaxis for cataract surgery: an evidence-based update. Ophthalmology, v. 109, n. 1, p. 13-24, 2002.

COOPER, S. C.; MCLELLAN, G. J.; RYCROFT, A. N. Conjunctival flora observed in 70 healthy domestic rabbits (Oryctolagus cuniculus). The Veterinary Record, v. 149, p. 232-235, 2001.

CULLEN, C. L. Normal ocular features, conjunctival microflora and intraocular pressure in the Canadian beaver (Castor canadensis). Veterinary Ophthalmology, v. 6 , n. 4, p. 279-284, 2003.

CULLEN, C. L.; IHLE, S. L.; WEBB, A. A.; MCCARVILLE, C. Keratoconjunctival effects of diabetes mellitus in dogs. Veterinary Ophthalmology, v. 8, n. 4, p. 215224, 2005.

CULLEN, C. H.; WEBB, A. Ocular manifestations of systemic disease Part 1: the dog. In: GELATT, K. N. Veterinary ophthalmology. 4. ed. lowa: Blackwell Publishing, 2007a. p.1470-1537.

CULLEN, C. H.; WEBB, A. Ocular manifestations of systemic disease Part 2: The cat. In: GELATT, K. N. Veterinary ophthalmology. 4. ed. lowa: Blackwell Publishing, 2007b. p. 1538-1587. 
DAVIDSON, M. G.; NELMS, S. R. Diseases of the canine lens and cataract formation. In: GELATT, K. N. Veterinary Ophthalmology. $4^{\text {th }}$ ed. lowa: Blackwell Publishing, 2007. p. 859-887.

EHLERS, N.; BULOW, N. Ocular complications to diabetes and their treatment. Acta Endocrinologica, v. 238, p. 59-66, 1980. Supplement.

EPSTEIN, D. L. Reversible unilateral lens opacities in a diabetic patient. Archives of Ophthalmology, v. 94, p. 461-463, 1976.

FARIA, P. F. Diabetes Mellitus em cães. Acta Veterinária Brasílica, v. 1, n.1, p. 822, 2007.

FELDMAN, E. C.; NELSON, R. W. Canine diabetes mellitus. In: Canine and feline endocrinology and reproduction. $3^{\text {rd }}$ ed.. Saint Louis: Elsevier Science, 2004, p. 486-538.

FELDMAN, E. C.; NELSON, R. W. Diabetes mellitus. In: Canine and feline endocrinology and reproduction. Philadelphia: WB Saunders, 1987, p. 261-294.

FRANCOIS, J.; RIJSSELAERE, M. Corticosteroids and ocular mycoses:

experimental study. Annals of ophthalmology, v. 6, n. 3, p. 207-217, 1974.

FREDRICKSON, A. G. Behavior of mixed cultures of microorganisms. Annual Review of Microbiology, v. 31, p. 63-88, 1977.

GALEGO, M. P.; SAFATLE, A. M. V.; BARROS, P. S. M. Comparação do pH e da quantidade de lágrima em cães normais e em diabéticos. CONGRESSO BRASILEIRO DA ANCLIVEPA 27., 2006, Vitória - ES, p. 83, 2006. Anais do XXVII Congresso Brasileiro da Anclivepa, 2006, p. 83.

GALERA, P. D.; ÁVILA, M. O.; RIBEIRO, C. R.; dos SANTOS, F. V. Estudo da microbiota da conjuntiva ocular de macacos-prego (Cebus apela - Linnaeus, 1758) e macacos bugio (Alouatta caraya - Humboldt, 1812), provenientes do reservatório de Manso, MT, Brasil. Revista do Instituto Biológico, v. 69, n. 2, p. 33-36, 2002.

GASKIN, J. M. Microbiology of the canine and feline eye. Veterinary Clinics of North America: Small Animal Practice, v. 10, n. 2, p. 303-316, 1980. 
GAYOSO, M. F. A.; OLIVEIRA, A. D. D.; AZEVEDO, P. A.; YU, M. C. Z.; HÖFLINGLIMA, M. C.; FRANCISCO, W. Suscetibilidade antimicrobiana in vitro dos Staphylococcus coagulase negativa oculares. Arquivos Brasileiros de Oftalmologia, v. 70, n. 6, p. 924-928, 2007.

GELATT, K. N. Doenças e cirurgia do segmento posterior In: Manual de oftalmologia veterinária. 1. ed. São Paulo: Editora Manole, 2003. p. 253-294.

GELVIN, J. B.; THONN, V. A. The formation and reversal of acute cataracts in diabetes mellitus. Journal of American Optometrists Association, v. 64, n. 7, p. 471-474, 1993.

GERDING JR, P. A.; KAKOMA, I. Microbiology of the canine and feline eye. Veterinary Clinics of North America: Small Animal Practice, v. 20, n. 3, p. 615625, 1990.

GLOVER, T. D.; CONSTANTINESCU, G., M. Surgery for cataracts. Veterinary Clinics of North American: Small Animal Pratice, v. 27, n. 5, p. 1143-1173, 1997.

GUM, G. G.; GELATT, K. N.; ESSON, D. W. Physiology of the eye. In: GELATT, K. N. Veterinary ophthalmology. 4. ed. lowa: Blackwell Publishing, 2007.

GUPTILL, L.; GLICKMAN, L.; GLICKMAN, N. Time trends and risk factors for Diabetes Mellitus in dogs: Analysis of Veterinary Medical Data Base Records (1970 1999). The Veterinary Journal, v. 165, n. 3, p. 240 - 247, 2003.

HAMMEKE, J. C.; ELLIS, P. P. Mycotic flora of the conjunctiva. American Journal of Ophthalmology, v. 49, p. 1174-1178, 1960.

HARTLEY, C.; WILLIAMS, D. L.; ADAMS, V. J. Effect of age, gender, weight, and time of day on tear production in normal dogs. Veterinary Ophthalmology, v. 9, n. 1 , p. $53-57,2006$.

HENDRIX, D. V. H. Canine conjuntiva and nictitating membrane. In: GELATT, K. N. Veterinary ophthalmology. 4. ed lowa: Blackwell Publishing, 2007. p. 662-689.

HSU, C.; WISEMAN, G. M. Antibacterial substances from staphylococci. Canadian Journal of Microbiology, v. 13, p. 947-955, 1967. 
IVANIC D.; MANDIC Z.; BARAC J.; KOPIC M. Cataract surgery and postoperative complications in diabetic patients. Collegium Antropulogicum, v. 29, p. 55-58, 2005.

KANELLOPOULOS, A. J.; DREYER, E. B. Postoperative infection following current cataract extraction surgery. International Ophthalmology Clinics.v. 36, n. 3, p. 97107, 1996.

KANEKO, J. J. New perspective in canine diabetes mellitus. California Veterinarian, v. 33, p. 24, 1979.

KATO S.; OSHIKA T.; NUMAGA J.; HAYASHI Y.; OSHIRO M.; YUGUCHI T.; KAIYA $\mathrm{T}$. Anterior capsular contraction after cataract surgery in eyes of diabetic patients.

British Journal of Ophthalmology, v. 85, n. 1, p. 21-23, 2001.

KREEGER-VAN-RIG, N. J. W. The yeasts: a taxonomic study. 3. ed. Amsterdan: Elsevier Science Publisher, 1984. 1082 p.

KRIEG, N. R.; HOLT, J.C. Bergey's manual of sistematic bacteriology. 9. ed. Baltimore: Williams e Wilkins, 1994. 984 p.

KUDIRKIENE, E.; ZILINSKAS, H.; SIUGZDAITE, J. Microbial flora of the dog eyes, Veterinarija ir Zootechnika, v. 34, n. 36, p. 18 - 21, 2006.

LANDRY, M. P.; HERRING, I. P.; PANCIERA, D. L. Fundoscopic findings following cataract extraction by means of phacoemulsification in diabetic dogs: 52 cases (1993-2003). Journal of American Veterinary Medical Association, v. 225, n. 5, p. 709-716, 2004.

LARONE, D. H. Medically important fungi: a guide to identification.3. ed. Washington: ASM Press, 1995. 430 p.

LAUS, J. L.; TORRECILHAS, A.; BRUNELLI J.; ORIÁ, A. P.; ALMEIDA, D. E.; TALIERI, I. C. Afecções da lente. In: HERRERA D. Oftalmologia clínica em animais de companhia. 1. ed. São Paulo: MedVet Livros, 2008, p.141-154. 
LENNETE, E. H.; BALOWS, A.; HANSLER JR., W. J.; SHADOMY, H. J. Manual of clinical microbiology. 4. ed. Washington: American Society for Microbiology Press, 1985, p.1149

LODDER, L. The yeast: a taxonomic study. 2. ed. Amsterdam: North Holland Publishing, 1970, $1385 \mathrm{p}$.

MAMALIS, N.; ANDERSON, C. W.; KREISLER, K. R.; LUNDERGAN, M. K.; OLSON, $R$. J. Changing trends in the indications for penetrating keratoplasty. Archieves of Ophthalmology, v. 110, n. 10, p. 1409-1411,1992

MARMOR, M.; WILLEBERG, P.; GLIKMAN, L. T.; PRIESTER, W. A.; CYPESS R. H.; HURVITZ A. I. Epizootiologic patters of diabetes mellitus in dogs. American Journal of Veterinary Research, v. 43 p. 465-470, 1982.

MARTIN, C. L. Ocular infections. In: GREENE, C. E. Clinical microbiology and infeccious diseases of the dog and cat. Philadelphia: W. B. Saunders Co., 1984, p. 301-320.

MARTINS, E. N.; ALVARENGA, L. S.; HÖFLING-LIMA, A. L.; FREITAS, D.; ZORATYU, M. C.; FARAH, M. E.; MANNIS, M. J. Aerobic bacterial conjunctival flora in diabetic patients. Cornea, v. 23, n. 2, p. 136-142, 2004.

MCDONALD, P. J.; WATSON, A. D. J. Microbial flora of normal canine conjunctivae. Journal of Small Animal Practice, v. 17, p. 809-812, 1976.

MIRANDA, P. A. C.;REIS, R. Diabetes mellitus gestacional. Projeto Diretrizes Associação Médica Brasileira e Conselho Federal de Medicina. 2006. Disponível em: $<$ http://www.telessaudebrasil.org.br/lildbi/docsonline/6/3/036-

Diabetes Mellitus Gestacional.pdf>. Acesso em: 11 nov. 2008.

MOELLER, C. T. A.; BRANCO, B. C.; ZORAT-YU, M. C., FARAH, M. E.; SANTOS, M. A. A.; HÖFLING-LIMA, A. L. Evaluation of normal ocular bacterial flora with two different cuture media. Canadian Journal of Ophthalmology, v. 40, n. 4, p. 448453, 2005.

MURRAY, P. R.; BARON, E. J.; PFALLER, M.; TENOVER, F. C.; YOLKEN, R.H. Manual of clinical microbiology. 7 ed. Washington: American Society for Microbiology. 1999, p. 442-455. 
NARDONI, S.; SGORBINI, M.; BARSOTTI, G.; CORAZZA, M.; MANCIANTI, F. Conjunctival fungal flora in healthy donkeys. Veterinary Ophthalmology, v. 10, n. 4, p. 207-210, 2007.

NASISSE, M. P.; NELMS, S. Equine ulcerative keratitis. Veterinary Clinics of North America: Equine Practice, v. 8, n. 3, p. 537-555, 1992.

NASRI, F. Diabetes mellitus no idoso. In: FREITAS, E.V.; PY, L.; NERI, L.; CANÇADO, F. A. X.; GORZONI, M.; ROCHA, S. M. Tratado de geriatria e gerontologia. Rio de janeiro: Editora Guanabara Koogan, 2002, p. 496-501.

NEMA, H. V.; AHUJA, O. P.; BAL, A.; MOHAPATRA, L. N. Effects of topical costicosteroids and antibiotics on mycotic flora of conjunctiva. American Journal of Ophthalmology, v. 65, p. 747-750, 1968.

NERUP, J. On the pathogenesis of IDDM. Diabetologia, v. 37, p. S82-S89, 1994. Supplement 2.

NGUYEN, P.; DUMOND, H.; BIOURGE, V.; POUTACE, E. Measurement of postprandial incremental glucose and insulin changes in health dogs: influence of food adaptation and length of time of blood sampling. Journal of Nutrition, v. 128,n. 12, p. 2659s-2662s, 1998.

O'BRIEN, T. D.; BUTLER, P. C.; WESTERMARK, P.; JOHNSON, K. H. Islet amyloid polypeptide: a review of its biology and potential roles in the pathogenesis of diabetes mellitus. Veterinary Pathology, v. 30, n. 4, p. 317-332, 1993.

OSMAN, N. B.; JEDDI, A.; SEBAI, L.; ZGHAL, I.; KAOUECHE, M.; GAIGI, S.; AYED, S. La cornée du diabétique. Journal Francois d'Ophtalmologie, v. 18, n. 2, p. 120$123,1995$.

PISANI, E. H. R. Microbiota conjuntival normal de eqüinos. 1993. $41 \mathrm{f}$. Dissertação (Mestrado em Cirurgia) - Faculdade de Medicina Veterinária e Zootecnia, Universidade de São Paulo, São Paulo, 1993.

PORTE JR., D. B-cells in type II diabetes mellitus. Diabetes, v. 40, p. 166-180, 1991. 
PRADO, M. R.; ROCHA, M. F.; BRITO, E. H.; GIRÃO, M. D.; MONTEIRO, A. J.; TEIXEIRA, M. F.; SIDRIM, J. J. Survey of bacterial microrganisms in the conjuntivae saco of clinically normal dogs and dogs with ulcerative keratitis in Fortaleza, Ceará, Brazil. Veterinary Ophthalmology, v. 1, p. 33-37, 2005.

QUINN, P. J.; CARTER, M. E.; MARKEY, B.; CARTER, G. R. Staphylococcus.

Clinical veterinary microbiology. London: Mosby-Year Book Europe Limited. 1994, p. 112

RAND, J. S.; FLEEMAN, L. M.; FARROW, H. A.; APPLETON, D. J.; LEDERER, R. Canine and feline diabetes mellitus: nature or nurture? Journal Nutrition, n. 134, p. 2072-2080, Suplement, 2004.

RIJNBERK, A.; KOOISTRA, H. S.; MOL, J. A. Endocrine diseases in dogs and cats: similarities and differences with endocrine diseases in humans. Growth Hormone \& IGF Research, v. 13, p. 158-164, 2003.

RISS, R. C. Equine ophthalmology. In: GELATT, K. N. Veterinary ophthalmology. Philadelphia: Lea \&Febiger, 1981, p. 569-605.

ROLLINS, H. J.; STOCKER, F. W. Bacterial flora and preoperative treatment of donor corneas. American Journal of Ophthalmology, v. 59, p. $247-249,1965$.

ROSA, M.; CARDOZO, L. M.; PEREIRA, J. S. BROOKS, D. E.; MARTINS, A. L. B.; FLORIDO, P. S. S.; STUSSI, J. S. P. Fungal flora of normal eyes of helthy horses from state of Rio de Janeiro, Brazil. Veterinary Ophthalmology, v. 6, n. 1, p. 51 $55,2003$.

SAFATLE, A. M. V. Eletrorretinograma de campo total em cães diabéticos com catarata. 2008. 129 f. Tese (Doutorado em Medicina Veterinária) - Faculdade de Medicina Veterinária e Zootecnia, Universidade de São Paulo, São Paulo, 2008.

SAMUELSON, D. A.; ANDRESSEN, T. L.; GWIN, R. M. Conjunctival fungal flora in horses, cattle, dogs and cats. Journal of the American Veterinary Medical Association, v. 184, n. 10, p. $1240-1242,1984$.

SARCHAHI, A. A.; HAGHKHAH, M.; MOLAZEN, M. Antimicrobial susceptibility of canine normal conjunctival flora in Shiraz, Iran. 2005 <www.priory.com/vet/canineflora.html - 2005>. Acesso em: 13 mar. 2007. 
SUNARIC-MEGEVAND, G.; POURNARAS, C. J. Current approach to postoperative endophthalmitis. British Journal Ophthalmology. v. 81, n. 11, p. 1006-1015, 1997.

SLATTER, D. Fundamentals of veterinary ophthalmology. 2. ed. Philadelphia: W. B. Saunders, 1990. p. 204-225.

SPEAKER, M. G.; MILCH, F. A.; SHAH, M. K.; EISNER, W.; KREISWIRTH, B. N. Role of external bacterial flora in the pathogenesis of acute postoperative endophthalmitis. Ophthalmology. v. 98, n. 5, p. 639-649, 1991.

SUNARIC-MEGEVAND, G.; POURNARAS, C. J. Current approach to postoperative endophthalmitis. Brazilian Jounal of Ophthalmology, v. 81, n. 11, p. 1006-1015. 1997.

TA, C. N.; CHANG, R. T.; SINGH, K.; EGBERT, P. R.; SHRIVER, E. M.; BLUMENKRANZ, M. S.; KASPAR, H. M. de. Antibiotic resistance patters of ocular bacterial flora. Ophthalmology, v. 110, n. 10, p. 1946-1951, 2003.

TEIXEIRA, A. L.; MAIA, F. B. N.; ALVARENGA, L. S.; YU, M. C. Z.; HÖFLING-LIMA, A. L.; BARROS, P. S. M. Aerobic conjunctival flora of healthy dogs in Sao Paulo. Trabalho apresentado no $33^{\text {rd }}$ Annual Meeting of the American College of Veterinary Ophthalmologists, Denver, CO, USA, Abstract, Oct. 9-13, 2002. Veterinary Ophthalmology, v. 5, n. 4, p. 291, 2002.

THORENSEN, S. I.; BREDAL, W. P. Serum fructosamine measurement: a new diagnostic approach to renal glucosuria in dogs. Research in Veterinary Science, v. 67, p. 267-271, 1999.

URBAN, M.; WYMAN, M.;RHEINS, M.; MAVARRO, R. V. Conjunctival flora of clinically normal dogs. Journal of the American Veterinary Medical Association, v. 161 , p. 201-206, 1972

WANG, L.; PAN, Q.; ZHANG, L.; XUE, Q. CUI, J; QI, C. Investigation of bacterial microorganisms in the conjunctival sac of clinically normal dogs and dogs with ulcerative keratitis in Beijing, China. Veterinary Ophthalmology, v. 11, n. 3, p. 145149, 2008. 
WILKIE, D. A.; GEMENSKY-METZLER, A. J.; COLITZ, C. M. H.; BRAS, I. D.; KUONEN, V. J.; NORRIS, K. N.; BASHAM, C. R. Canine cataracts, diabetes mellitus and spontaneous lens capsule rupture: a retrospective study of 18 dogs. Veterinary Ophthalmology, v. 9, n. 5, p. 328-334, 2006.

YEE, R.W.; MATSUDA, M.; KERN, T. M.; ENGERMAN, R. L., EDELHAUSER, H. F. Corneal endothelial changes in diabetics dogs. Current Eye Research, v. 4, n. 7, p. 759-766, 1985. 